\title{
Involvement of formyl peptide receptors in receptor for advanced glycation end products (RAGE) - and amyloid beta 1-42-induced signal transduction in glial cells
}

\author{
Alexander Slowik,2, Julika Merres', Anne Elfgen', Sandra Jansen', Fabian Mohrr', Christoph J Wruck',
} Thomas Pufe ${ }^{1}$ and Lars-Ove Brandenburg ${ }^{1^{*}}$

\begin{abstract}
Background: Recent studies suggest that the chemotactic G-protein-coupled-receptor (GPCR) formyl-peptidereceptor-like-1 (FPRL1) and the receptor-for-advanced-glycation-end-products (RAGE) play an important role in the inflammatory response involved in neurodegenerative disorders such as Alzheimer's disease (AD).

Therefore, the expression and co-localisation of mouse formyl peptide receptor (mFPR) 1 and 2 as well as RAGE in an APP/PS1 transgenic mouse model using immunofluorescence and real-time RT-PCR were analysed. The involvement of rat or human FPR1/FPRL1 (corresponds to mFPR1/2) and RAGE in amyloid- $\beta$ 1-42 (Aß1-42)-induced signalling were investigated by extracellular signal regulated kinase 1/2 (ERK1/2) phosphorylation. Furthermore, the cAMP level in primary rat glial cells (microglia and astrocytes) and transfected HEK 293 cells was measured. Formyl peptide receptors and RAGE were inhibited by a small synthetic antagonist WRW4 and an inactive receptor variant delta-RAGE, lacking the intracytoplasmatic domains.
\end{abstract}

Results: We demonstrated a strong increase of mFPR1/2 and RAGE expression in the cortex and hippocampus of APP/PS1 transgenic mice co-localised to the glial cells. In addition, the Aß1-42-induced signal transduction is dependant on FPRL1, but also on FPR1. For the first time, we have shown a functional interaction between FPRL1/FPR1 and RAGE in RAGE ligands S100B- or AGE-mediated signalling by ERK1/2 phosphorylation and CAMP level measurement. In addition a possible physical interaction between FPRL1 as well as FPR1 and RAGE was shown with co-immunoprecipitation and fluorescence microscopy.

Conclusions: The results suggest that both formyl peptide receptors play an essential role in Aß1-42-induced signal transduction in glial cells. The interaction with RAGE could explain the broad ligand spectrum of formyl peptide receptors and their important role for inflammation and the host defence against infections.

Keywords: Alzheimer disease, Amyloid beta 1-42, S100B, Formyl peptide receptor, Glial cell, Astrocytes, Microglia, RAGE, Signal transduction

\footnotetext{
* Correspondence: Ibrandenburg@ukaachen.de

'Department of Anatomy and Cell Biology, RWTH Aachen University,

Wendlingweg 2, 52074 Aachen, Germany

Full list of author information is available at the end of the article
} 


\section{Background}

Alzheimer's disease (AD) is a neurodegenerative disorder characterised by senile plaques and neurofibrillary tangles. An important component of the plaques in the human brain is amyloid- $\beta$ 1-42 (A $\beta 1-42)$, a 42 amino acid peptide fragment derived from sequential proteolytic cleavage of the amyloid precursor protein by beta- and gamma-secretases [1]. A $\beta 1-42$ plays a central role in mediating neurotoxicity and activates glial cells (astrocytes as well as microglia). Elevated levels of non-fibrillar $[2,3]$ and fibrillar $A \beta 1-42[4,5]$ lead to the release of proinflammatory cytokines by activated glial cells. This may subsequently lead to gliosis and cytotoxicity in neurons [6-8]. However, the role of glial cells in the formation of amyloid plaques in Alzheimer's disease remains unknown $[9,10]$. The underlying pathogenic mechanisms are not well understood, especially regarding the initial steps of cellular A 1-42 uptake and the induction of signal transduction and the consequence for the development of the disease. Recent studies suggest that the chemotactic Gprotein-coupled receptor, formyl-peptide-receptor-like 1 (FPRL1), is involved in $\mathrm{A} \beta 1-42$ and $\operatorname{PrP}_{106-126}$-induced activation and the internalisation in glial cells [11-13]. Furthermore it is indicated that the FPRL1 is expressed on astrocytes and microglia and plays an essential role in the inflammatory response [14].

However, it should be noted that a variety of further receptors were discussed to participate in $A \beta 1-42-$ induced glial cell activation and internalisation. In fact, previous results suggest an involvement of the scavenger receptor MARCO (macrophage receptor with collagenous structure) $[15,16]$ and the receptor for advanced glycation endproducts (RAGE)[17]. MARCO is a membrane glycoprotein that can bind to chemically modified low-density lipoproteins or Gram-positive and Gram negative bacteria $[18,19]$. For MARCO, our recent work shows no involvement in A $\beta 1-42$-induced glial cell activation [11]. However, we are able to show a physical and functional interaction between FPRL1 and MARCO in MARCO ligand fucoidan-induced signaling and in the host defense against brain infections [11,14]. RAGE is a multiligand receptor belonging to the immunoglobulin superfamily [20].

In this study we analysed the expression of formyl peptide receptors and RAGE and their glial localisation using fluorescence microscopy and real-time RT-PCR in an APP/PS1 transgenic mouse model. The murine FPR gene family has at least six members in contrast to only three in humans. Fpr1 encodes for the murine FPR1 (mFPR1), which is considered to be the murine orthologue of human FPR1, whereas Fpr-rs2 (mFPR2) encodes for receptors that are similar to the human formyl peptide receptor like 1 (FPRL1) [21]. Furthermore, we examined the involvement of FPRL1, FPR1 and RAGE in
A $\beta 1-42$-induced signalling by measured the extracellularsignal regulated kinase 1/2 (ERK 1/2) phosphorylation and cAMP levels in rat glial and transfected HEK293 cells. Also, the involvements of the RAGE receptor ligands S100B as well as AGE-induced signalling were examined. In addition, a functional and physical interaction between FPR1, FPRL1 and RAGE using co-immunoprecipitation and ERK1/2 phosphorylation and cAMP level measurement in rat glial and transfected HEK293 cells was determined. Furthermore, we analysed and quantified the co-localisation between different receptors and S100B or A $\beta 1-42$ in transfected HEK293 cells using fluorescence microscopy. The results suggest that FPRL1 as well as FPR1 play an essential role in A $\beta 1-42$-induced signal transduction in glial cells, and also show the capability of formyl peptide receptors to expand its ligand spectrum by interacting with the RAGE receptor.

\section{Methods}

\section{Reagents}

Human $A \beta 1-42$ and formyl-peptide-receptor antagonist WRW4 [22] were purchased from Dr. P. Henklein (Charité, Berlin, Germany). Peptides were dissolved at 1 and $10 \mathrm{mM}$ concentration in dimethylsulfoxide (DMSO), and A $\beta 1-42$ is present in the soluble form. DMSO used as vehicle in a concentration of $0.1 \%$ showed no significant effects in the experiments. The RAGE agonists Advanced Glycation Endproduct-Bovine Serum Albumine (AGE-BSA) and S100 calcium binding protein B (S100B) were purchased from BioCat (Heidelberg, Germany) and Merck (Darmstadt, Germany). Forskolin and formyl-methionyl-leucyl-proline (fMLF) were obtained from Sigma-Aldrich, Munich, Germany.

\section{APP/PS1 transgenic mouse model}

The APP/PS1 transgenic mouse model used in this study (APPswe/PS1dE9-Line 85) co-expresses a chimeric mouse/ human amyloid precursor protein (APP) 695 harboring the Swedish K670M/N671L mutations (Mo/HuAPPswe) and human presenilin 1 (PS1) with the exon-9 deletion mutation (PS1dE9) under control of the mouse prion protein promoter [23]. The mouse line was obtained from Jackson Laboratory (B6.Cg-Tg(APPswe,PSEN1dE9) 85Dbo/J; Stock-Number: 005864; Promoter: Prnp, prion protein; created by David Borchelt 2006, University of California, referring to Jackson Laboratory). Wildtype littermates were used as controls. Mice were used at 12 months of age. Mice were fed standard lab chow and water ad libitum and kept under a $12 \mathrm{~h}$ light/dark cycle.

\section{Cloning of CDNA and plasmids}

The pcDNA3.1-hFPRL1 plasmid containing a neomycin resistance gene was kindly provided by Dr. U. Rescher (Münster, Germany). The pcDNA3.1-hFPR1 containing 
a neomycin resistance gene was obtained from UMS cDNA Resource Center (Rolla, Missouri, USA). The pcDNA3.1hRAGE and -hRAGE $\Delta$ cyto plasmids, containing a neomycin resistance gene, were kindly provided by Prof. $R$. Donato (Perugia, Italy). RAGE $\Delta$ cyto ( $\triangle$ RAGE) is a RAGE mutant lacking the cytoplasmic domain [24]. The inserts were subcloned into a pcDNA3.1 expression vector containing a Zeocin $^{\mathrm{TM}}$ resistance gene (Invitrogen, Karlsruhe, Germany).

\section{Cell culture}

HEK293 cells (American Type Culture Collection, Rockville, MD, USA) were subcultivated in Dulbecco's modified Eagle's medium (DMEM; PAA Laboratories, Pasching, Austria) supplemented with $10 \%$ fetal calf serum (FCS) and 1\% penicillin/streptomycin (Carl Roth, Karlsruhe, Germany). The transfection and selection of HEK293 cells expressing hFPRL1 was described previously [11]. Using Lipofectamine 2000 (Invitrogen, Karlsruhe, Germany) according to the manufacturer's protocol, HEK293 cells (American Type Culture Collection, Rockville, MD, USA) were first transfected with either pcDNA3.1-hFPR1 or hFPRL1 plasmid. Stable transfectants were selected in the

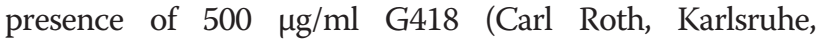
Germany). To generate hFPR1/hFPRL1 cell lines coexpressing hRAGE or hRAGE $\Delta$ cyto, cells were subjected to a second round of transfection with pcDNA3.1-hRAGE or -hRAGE $\Delta$ cyto and selected in the presence of $100 \mu \mathrm{g} / \mathrm{ml}$ Zeocin $^{\mathrm{TM}}$ (Invitrogen, Karlsruhe, Germany).

Isolated cerebral cortices and rostral mesencephali from wistar rats (P2) were stripped of the meninges, minced and dissociated enzymatically with trypsin from bovine pancreas (Sigma-Aldrich, Taufkirchen, Germany) in phosphate-buffered saline and $50 \mu \mathrm{g} / \mathrm{ml}$ DNase I (Roche Molecular Biochemicals, Mannheim, Germany) for $30 \mathrm{~min}$ at $37^{\circ} \mathrm{C}$ and crushed mechanically with Pasteur pipettes. Astrocytes were prepared according to the protocol of McCarthy and DeVellis [25], which allows the preparation of nearly pure cultures of astrocytes (> 97\%) and cultivated in Dulbecco's modified Eagle's medium (DMEM; PAA Laboratories, Pasching, Austria) supplemented with $10 \%$ FCS. Suspended microglial cells were plated in $75 \mathrm{~cm}^{2}$ cell culture flasks (Sarstedt, Nümbrecht, Germany) in microglial cell growth medium and harvested as described previously [13]. The microglial cell growth medium (DMEM) containing $10 \%$ FCS (heat inactivating from $44-53^{\circ} \mathrm{C}$ ) and antibiotics (penicillin and streptomycin). After about ten days, the cells begin to move away from the cell layer and swim in the supernatant. The cells are collected and then seeded in normal medium (DMEM, 10\% FCS heat inactivated at $56^{\circ} \mathrm{C}$, penicillin and streptomycin). Prior to replating microglial cells for different assays, cell number and viability were estimated by trypan blue exclusion. This procedure increased the purity of the microglial preparation to $>98 \%$ with only very few remaining astrocytes.

\section{RNA isolation and real time RT-PCR}

Total RNA was isolated using the peqGold Trifast reagent (Peqlab, Erlangen, Germany) according to the manufacturer's instructions. RNA samples were reversetranscribed by moloney murine leukemia virus (MMLV) reverse transcriptase (Fermentas, Burlington, Canada) and random hexamer primers (Invitrogen, Darmstadt, Germany). The cDNA products were used immediately for SYBR green (Applied Biosystems, Darmstadt, Germany) real-time RT-PCR for mus(m)FPR1, mFPR2 and RAGE. Gene expression was monitored using the StepOne Plus apparatus (Applied Biosystems, Darmstadt, Germany) according to manufacturer's protocol [26]. Relative quantification was performed using the $\Delta \mathrm{Ct}$ method which results in ratios between target genes and a housekeeping reference gene (18 s). cDNA was amplified using gene-specific primers described in Table 1. The specificity of the amplification reaction was determined by a melting curve analysis. We performed relative quantification of the signals normalising to the Geomean of the gene signal from $\mathrm{m} 18 \mathrm{~s}$, ribosomal protein L13a (RPL13a) and TATA box binding protein (TBP; all primers Eurofins MWG Operon, Ebersberg, Germany, for primer sequences please see Table 1) for SYBR Green real time RT-PCR.

\section{Western blotting}

For Western blot analysis of MAP kinase phosphorylation, rat glial or HEK293 cells were seeded in DMEM containing 10\% FCS. Cells were harvested in a lysis buffer (50 mM Tris pH 7.5, $100 \mathrm{mM} \mathrm{NaCl}, 5$ mM EDTA, 1\% Triton, $2 \mathrm{mM}$ sodium orthovanadate, $2.5 \mathrm{mM}$ sodium pyrophosphate, $1 \mathrm{mM}$ glycerol 2-phosphate, $1 \mathrm{mM}$ phenylmethylsulfonylfluoride). Proteins ( $5 \mu \mathrm{g}$ for $\mathrm{pERK}$ and ERK2) were resolved in SDS sample buffer, and a Western blotting procedure was performed as previously described in detail [12]. Membranes were incubated with polyclonal primary antibodies against pERK1/2 (1:500; sc-7383; Santa Cruz Biotechnology, Santa Cruz, CA, USA) overnight at $4^{\circ} \mathrm{C}$ and subsequent detection was performed with peroxidase-labeled secondary antibodies (SigmaAldrich, Munich, Germany). Antibody binding was detected by enhanced chemiluminescence (Amersham Pharmacia Biotech, Essex, UK). The membranes were then stripped and re-probed with anti-ERK2 (1:500; sc1647; Santa Cruz Biotechnology, Santa Cruz, CA, USA) antibody as a loading control. The Western blot bands were densitometrically evaluated with the program Quantity One (Bio-Rad, Munich, Germany), the pERK-bands were adjusted with their respective ERK-bands and subsequently, the values were referred to control $(=100 \%)$. 
Table 1 Primer sequences for real-time RT-PCR gene analysis

\begin{tabular}{|c|c|c|c|}
\hline primer & & sequence & annealing $\operatorname{Tm}\left[{ }^{\circ} \mathrm{C}\right]$ \\
\hline \multirow[t]{2}{*}{ mFPR1 } & for & 5'-CACAATCCAAGTCCGTGAACG-3' & 57 \\
\hline & rev & 5'-CAGCTGTTGAAGAAAGCCAAGG-3' & \\
\hline \multirow[t]{2}{*}{ mFPR2 } & for & 5'-CTGAATGGATCAGAAGTGGTGG-3' & 56 \\
\hline & rev & 5'-CCCAAATCACTAGTCCATTGCC-3' & \\
\hline \multirow[t]{2}{*}{ mRAGE } & for & 5'-TGACCGCAGTGTAAAGAGTCCC-3' & 59 \\
\hline & rev & 5'-CCCTTAGCTGGCACTTAGATGG-3' & \\
\hline \multirow[t]{2}{*}{ m18s } & for & 5'-GAATAATGGAATAGGACCGCGG-3' & 57 \\
\hline & rev & 5'-AAGAATTCACCTCTAGCGGCG-3' & \\
\hline \multirow[t]{2}{*}{ mTBP } & for & 5'-AGAACAATCCAGACTAGCAGCA-3' & 58 \\
\hline & rev & 5'-GGGAACTTCACATCACAGCTC-3' & \\
\hline \multirow[t]{2}{*}{ mRPL13a } & for & 5'-GAATAATGGAATAGGACCGCGG-3' & 60 \\
\hline & rev & 5'-GGCTCGGAATTGGTAGGGG-3' & \\
\hline
\end{tabular}

\section{Co-immunoprecipitation}

Co-immunoprecipitation was performed as previously described in detail in Brandenburg et al. 2010 [10]. Cells $\left(1.5 \times 10^{6} /\right.$ plates for astrocytes and transfected HEK293 cells, $10 \times 10^{6} /$ plates for microglia) were plated onto $100 \mathrm{~mm}$ dishes and grown to $80 \%$ confluence. Cells were washed twice with phosphate-buffered saline and harvested into ice-cold lysis buffer $(10 \mathrm{mM}$ Tris- $\mathrm{HCl}, \mathrm{pH}$ 7.6, 5 mM EDTA, 3 mM EGTA, 250 mM sucrose, $10 \mu \mathrm{M}$ iodoacetamide, and a mixture of proteinase inhibitors: $0.2 \mathrm{mM}$ phenylmethylsulfonyl fluoride, $10 \mu \mathrm{g} / \mathrm{ml}$ leupeptin, $1 \mu \mathrm{g} / \mathrm{ml}$ pepstatin A, $1 \mu \mathrm{g} / \mathrm{ml}$ aprotinin, and $10 \mu \mathrm{g} / \mathrm{ml}$ bacitracin). Subsequently, the cell suspensions were incubated for $30 \mathrm{~min}$ on ice and homogenised. The homogenates were then centrifuged at $500 \mathrm{~g}$ for $5 \mathrm{~min}$ at $4^{\circ} \mathrm{C}$ to remove not disrupted cells and nuclei. Membranes were pelleted at $20.000 \mathrm{~g}$ for $30 \mathrm{~min}$ at $4^{\circ} \mathrm{C}$, and pellets were lysed in detergent buffer (20 mM HEPES, pH 7.4, $150 \mathrm{mM} \mathrm{NaCl}, 5 \mathrm{mM}$ EDTA, 3 mM EGTA, $4 \mathrm{mg} / \mathrm{ml} \beta-$ dodecylmaltoside, and the proteinase inhibitors listed above) for $1 \mathrm{~h}$ on ice. Lysates were centrifuged at $20.000 \mathrm{~g}$ for $30 \mathrm{~min}$ at $4^{\circ} \mathrm{C}$, and the protein content of the resulting supernatant was determined using a BCA protein assay (Pierce, Rockford, IL, USA). Receptor proteins were immunoprecipitated with $50 \mu \mathrm{l}$ protein $\mathrm{G}$ agarose beads preloaded with $5 \mu \mathrm{g}$ anti-FPR1 or anti-FPRL1 antibodies (for rat glial cells from Santa Cruz; for HEK cells transfected with hFPR1 or hFPRL1, from MBL, Woburn, MA, USA or Abcam (FPRL1, ab13177)) overnight at $4^{\circ} \mathrm{C}$. Beads were washed five times with detergent buffer and eluted into $200 \mu \mathrm{l}$ of SDS-sample buffer $(62.5 \mathrm{mM}$ Tris- $\mathrm{HCl}$, pH 6.8, 2\% SDS, 20\% glycerol, 100 mM DL-dithiotreitol, and $0.005 \%$ bromphenol blue) at $60^{\circ} \mathrm{C}$ for $20 \mathrm{~min}$. After SDS-polyacrylamide gel electrophoresis and electroblotting, membranes were incubated with rabbit anti-FPR1, FPRL1, RAGE (Abcam, Cambridge, UK; ab3611) antibodies overnight at $4^{\circ} \mathrm{C}$. Immunoreactive bands were visualized using the enhanced chemiluminescence detection system mentioned above.

\section{Determination of receptor activity by measuring cyclic AMP accumulation}

$5 \times 10^{4}$ astrocytes/well, or $7.5 \times 10^{4} \mathrm{microglia} /$ well or $1.5 \times 10^{4}$ transfected HEK cells were seeded in a 96 well culture plate with DMEM containing 10\% FCS and incubated for $48 \mathrm{~h}$. The medium was removed and replaced with $100 \mu \mathrm{l}$ of serum-free Opti-MEM medium containing $10 \mu \mathrm{M}$ forskolin (for astrocytes, Sigma) or $25 \mu \mathrm{M}$ forskolin (for microglial or HEK cells) plus agonist. Different forskolin concentrations were used because there is a difference in cell sensitivities to forskolin-stimulated adenylate cyclase activity. For the formyl peptide receptors antagonist WRW4, glial cells were pre-incubated in OptiMEM medium containing $10 \mu \mathrm{M}$ WRW4 for $30 \mathrm{~min}$. The cells were incubated at $37^{\circ} \mathrm{C}$ for $15 \mathrm{~min}$, and the reaction was terminated by the removal of the culture medium and addition of $70 \mu \mathrm{l}$ lysis buffer (for HEK cells) or $100 \mu \mathrm{l}$ lysis buffer (for glial cells) followed by $10 \mathrm{~min}$ incubation at room temperature. cAMP content was determined using a commercial available colorimetric kit (Millipore, Schwalbach, Germany).

\section{Fluorescence microscopy}

Formalin-fixed and paraffin-embedded $5 \mu \mathrm{m}$ whole coronary brain sections were examined. For immunofluorescence staining, sections were deparaffinized, pretreated for $3 \times 7$ min with microwaving in citric acid buffer, permeabilized with $0.1 \%$ Triton $\mathrm{X}$ in PBS for $10 \mathrm{~min}$ at room temperature and after blocking with $1.5 \%$ bovine serum albumine (BSA; Sigma-Aldrich, Taufkirchen, Germany) in TRIS incubated with either polyclonal rabbit anti-mFPR1 (1:100; ab101701; Abcam, Cambridge, UK), anti-mFPR2 (1:100; sc-18191; Santa Cruz Biotechnology), anti-RAGE (1:100; ab3611; Abcam, Cambridge, 
UK) and monoclonal mouse anti-GFAP (1:250; ab10062; Abcam, Cambridge, UK) or polyclonal goat anti-Iba1 (1:100; ab5076; Abcam, Cambridge, UK) overnight at $4^{\circ} \mathrm{C}$. Finally, the slices were incubated with donkey antirabbit AlexaFluor 488 (Molecular Probes, Darmstadt, Germany) and goat anti mouse Cy3 (Sigma-Aldrich, Taufkirchen, Germany) or rabbit anti-goat AlexaFluor 555 (all 1:250; Molecular Probes, Darmstadt, Germany) for $1 \mathrm{~h}$ at room temperature.

\section{Fluorescence staining of primary and cell cultures}

Glial or HEK293 cells were grown on glass coverslips. Coverslips were previously coated with poly-L-lysine according the instruction (Sigma-Aldrich, Munich, Germany). Transfected HEK293 cells were exposed to RAGE agonist S100B $(5 \mu \mathrm{g} / \mathrm{ml}=2.4 \mu \mathrm{M})$ for $2 \mathrm{~h}$ at $37^{\circ} \mathrm{C}$. After fixation with $4 \%$ paraformaldehyde and $0.2 \%$ picric acid in a phosphate buffer at $\mathrm{pH} 6.9$ [11] for $30 \mathrm{~min}$ and permeabilisation with $0.1 \%$ TritonX in PBS, cells were blocked in $0.1 \mathrm{M}$ Tris- $\mathrm{HCl}$ pH 7.5 containing 1.5\% BSA for 10 min. Coverslips were incubated at $4^{\circ} \mathrm{C}$ overnight with primary antibodies for FPR, FPRL1 or RAGE (for rat glial cells: FPR/ FPRL1 from Santa Cruz; RAGE from AbD Serotec, Düsseldorf, Germany (goat) or Abcam (rabbit); for transfected HEK cells: hFPR1 from MBL (rabbit) or Santa Cruz (goat); hFPRL1 from Abcam (rabbit) or Everest Biotech, Oxfordshire, UK (goat); RAGE from AbD Serotec and S100B from Abcam (ab868, rabbit); A $\beta 1-42$ from Santa Cruz (sc-58495, mouse) and diluted in TRIS containing 1.5\% BSA. Finally, the coverslips were incubated with donkey anti-rabbit or anti-goat AlexaFluor 488 (Molecular Probes, Darmstadt, Germany) and goat anti rabbit Cy3 (Millipore) or rabbit anti-goat AlexaFluor 555 (all 1:250; Molecular Probes, Darmstadt, Germany) for $1 \mathrm{~h}$ at room temperature. Nuclear staining was performed with bisbenzimide (Sigma-Aldrich, Taufkirchen, Germany). Cells were digitally photographed using a LSM7 DUO laser confocal microscope (Zeiss, Göttingen, Germany).

\section{Determination of co-localisation}

The Pearson coefficient is a measure of the strength of linear relationship between two signals. Instead, Spearman coefficient is a measure of how well any monomeric function between the variables can describe the relationship. The Pearson-Spearman correlation (PSC) co-localisation plugin for ImageJ was used to calculate co-localisation between target receptors RAGE, FPR1 or FPRL1 and S100B or A 1-42 [27,28]. A subselection as a region of interest (ROI) was set up around the plasma membrane using the Selection Brush with a width of 25 pixels. The value for the background intensity noise threshold was set up to 40 to calculate the coefficients.

\section{Statistical analysis}

All in vitro experiments were performed at least in triplicate and the values are expressed as mean \pm SEM. For statistical comparison, ANOVA test was used followed by Bonferroni's correction. A value of $\mathrm{p}<0.05$ was considered statistically significant. The GraphPad Prism 5.0 software was used for statistical calculation (Graph Pad Software, San Diego, CA, USA).

\section{Results}

Increased formyl peptide receptors and RAGE expression in glial cells in an APP/PS1 transgenic mouse model

In a first set of experiments we investigated the expression and localisation of the mouse formyl peptide receptors mFPR1 and mFPR2 as well as RAGE in an APP/PS1 transgenic mouse model of AD. We used double fluorescence microscopy with receptor and glial cell (GFAP for activated astrocytes and Iba- 1 for microglia/macrophages) specific antibodies to localise the receptor expression in mouse brain sections. The receptor expression was analysed in the cortex and hippocampus of twelve month old double transgenic mice co-expressing human PS1dE9 and mouse/human (mo/hu) chimeric APP695 (humanized A $\beta$ domain) harboring the Swedish (K594M/N595L) mutation [23] and compared with wildtype littermates. As shown in figure 1 and 2, only few GFAP- and Iba-1immunoreactive cells and very little mFPR1 (Figures 1A and $2 \mathrm{~A}$ ), mFPR2 (Figures $1 \mathrm{~B}$ and $2 \mathrm{~B}$ ) as well as RAGE (Figures $1 \mathrm{C}$ and $2 \mathrm{C}$ ) immunoreactivity were detected in the wildtype cortex and hippocampus. In contrast, the brain slices of contemporary APP/PS1 transgenic mice showed a strong increase of both GFAP and Iba- 1 immunoreactivity in the cortex and hippocampus. For mFPR1, in the cortex the GFAP positive cells showed a slight and in the hippocampus a clear increase of mFPR1 immunofluorescence (Figure 1A). A significant mFPR1 expression in brain slices of cortex and hippocampus co-localised with Iba1-positive cells was detected (Figure 2A). For mFPR2, a strong increase of immunoreactivity was evident in GFAP- as well as Iba-1-positive cells in the cortex and hippocampus of APP/PS1 transgenic mice (Figures $1 \mathrm{~B}$ and $2 \mathrm{~B}$ ). For RAGE, the immunoreactivity was strongest in the hippocampus in GFAP- and Iba1positive cells, but also in the cortex, an increase was detected (Figures $1 \mathrm{C}$ and $2 \mathrm{C}$ ). Please not that we did not have observe a clear increase of receptor expession in the near of the plaques.

To confirm the immunofluorescence studies, the mRNA expression of mFPR1, mFPR2 and RAGE in the two brain regions cortex and hippocampus was quantified using realtime RT-PCR in APP/PS1 transgenic mice compared to wildtype littermates. As shown in Figure 3A, the mFPR1 mRNA expression was significantly increased in the hippocampus and cortex of the APP/PS1 transgenic mice 

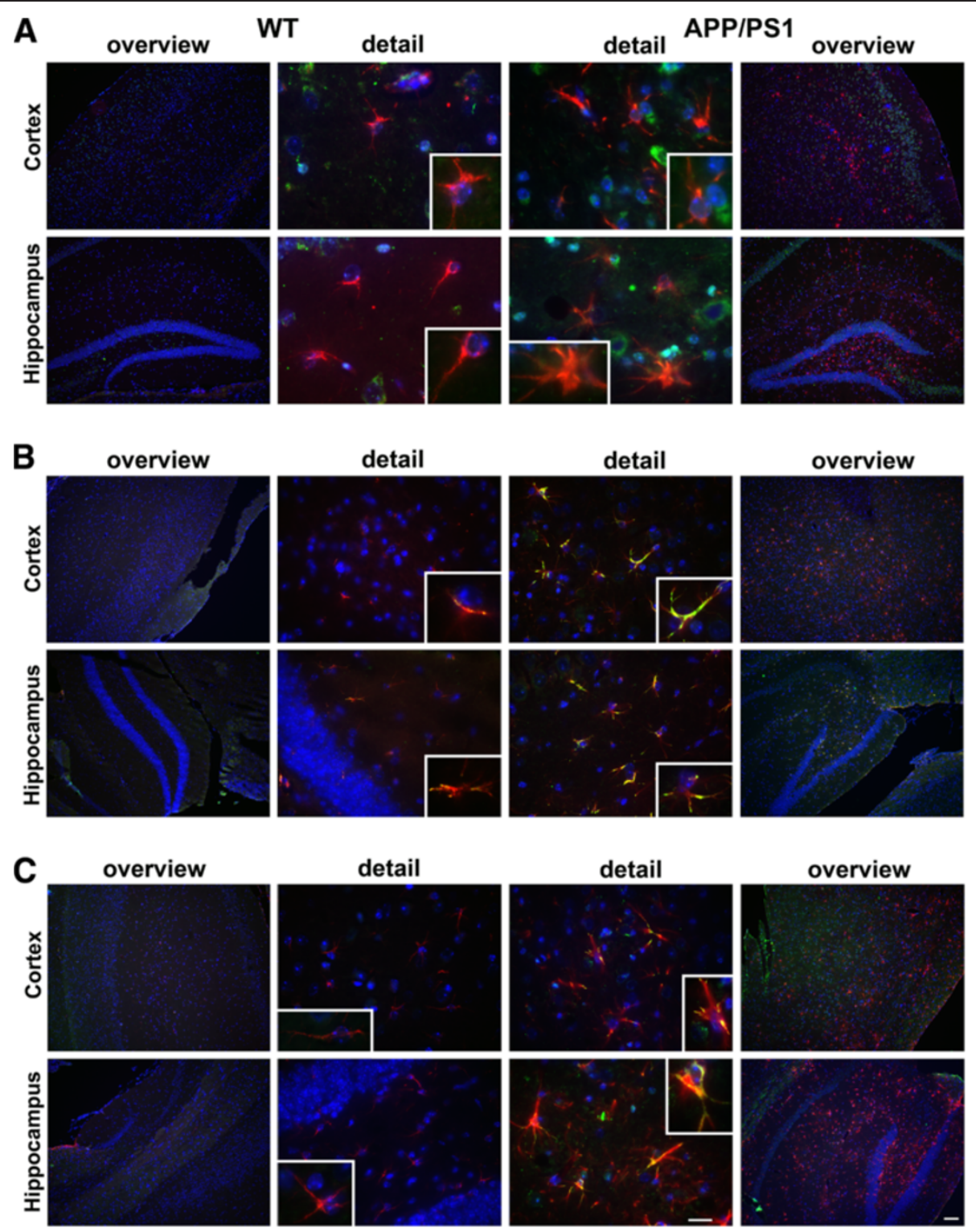

Figure 1 Increased formyl peptide receptors and RAGE expression in astrocytes in a APP/PS1 transgenic mouse model. Coronal brain sections from twelve month old APPswe/PS1dE9 (APP/PS1) or wildtype (WT) mice were stained with anti-glial fibrillary acidic protein (GFAP) to identify astrocytes (red) and anti-mFPR1 (A), anti-mFPR2 (B) or anti-RAGE (C) (green) antibodies (nuclear counterstaining in blue). The figures show representative results for the cortex and hippocampus from one of three independent experiments (Scale bar $=200 \mu \mathrm{m}$ for overview and $20 \mu \mathrm{m}$ for detailed images).

(cortex: $8.5 \pm 1.6$ fold increase; hippocampus: $5.9 \pm$ $1,5$ fold increase, $\mathrm{p}<0.01$ and $\mathrm{p}<0.05$; Figure $3 \mathrm{~A})$. For mFPR2, the expression was significantly increased in the cortex as well as the hippocampus (cortex: $9.8 \pm 2.3$ fold increase; hippocampus: $8.3 \pm 1.7$ fold increase, both $\mathrm{p}<0.01$; Figure 3B). For RAGE, the maximum induction of expression was detected in the hippocampus, whereas in the cortex also a significant increase was determined (cortex: $15.8 \pm 3.5$ fold increase; hippocampus: $30.5 \pm 10.6$ fold increase, $\mathrm{p}<0.01$ and $\mathrm{p}<0.05$; Figure $3 \mathrm{C}$ ).
Inhibition of RAGE-induced signal transduction by formyl peptide receptor antagonist WRW4 in glial cells

We were able to detect an increased receptor expression for formyl peptide receptors (mFPR1 and mFPR2) and RAGE in the APPswe/PS1dE9 mice. In the next step we investigated the glial cell activation by the different receptor ligands. Therefore, we incubated primary rat astrocytes and microglial cells with A $\beta 1-42$ and fMLF as formyl peptide receptor agonists and $\mathrm{S} 100 \mathrm{~B}$ and AGE-BSA as RAGE agonists to determine ERK1/2 phosphorylation and the inhibition of forskolin-induced cAMP accumulation. The 

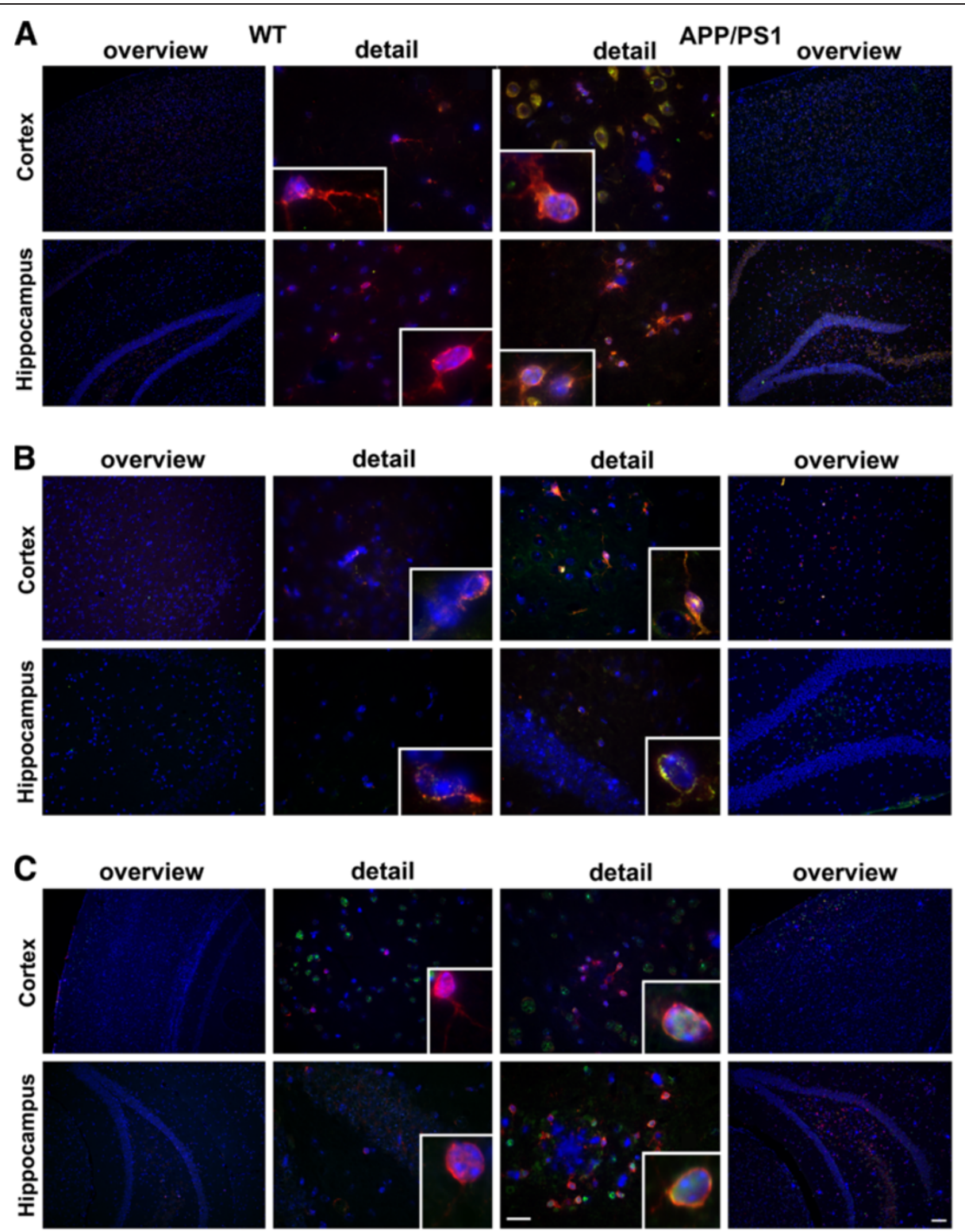

Figure $\mathbf{2}$ Increased formyl peptide receptors and RAGE expression in microglial cells in a APP/PS1 transgenic mouse model. Coronal brain sections from twelve month old APPswe/PS1dE9 (APP/PS1) or wildtype (WT) mice were stained with anti-ionized calcium binding adaptor molecule-1 (anti-lba-1) to identify microglial cells (red) and anti-mFPR1 (A), anti-mFPR2 (B) or anti-RAGE (C) (green) antibodies (nuclear counterstaining in blue). The figures show representative results for the cortex and hippocampus from one of three independent experiments (Scale bar $=200 \mu \mathrm{m}$ for overview and $20 \mu \mathrm{m}$ for detailed images).

rat glial cells express FPR1 (homologous to mFPR1) and FPRL1 (homologous to mFPR2)[11]. As shown in Figure 4A to D, treatment with A $\beta 1-42$ and fMLF as well as S100B and AGE-BSA resulted in an intense phosphorylation of ERK1/2 in glial cells. The formyl peptide receptor antagonist WRW4 inhibited the A $31-42$ - and fMLF-induced ERK1/2 phosphorylation in astrocytes as well as microglia cells. This confirmed our previous results $[11,13]$. In addition, the present work showed that the S100Band AGE-BSA-induced ERK1/2 phosphorylation is also inhibited by WRW4, which has no effect on ERK1/2 phosphorylation by itself. In addition to the ERK1/2 phosphorylation mentioned, the formyl peptide receptors capacity to inhibit cAMP formation was investigated. The formyl peptide receptors are coupled to inhibitory Gprotein $\left(G_{i}\right)$. The activation resulted in a reduction of cAMP level. Forskolin was used as the activator of the adenylate cyclase [12]. To determine whether the different agonists inducing cAMP formation is linked via $G_{i}$ receptor activity, the cAMP production in glial cells was induced by forskolin treatment, and the interference of A $11-42$, fMLF, S100B and AGE-BSA was analysed. As 

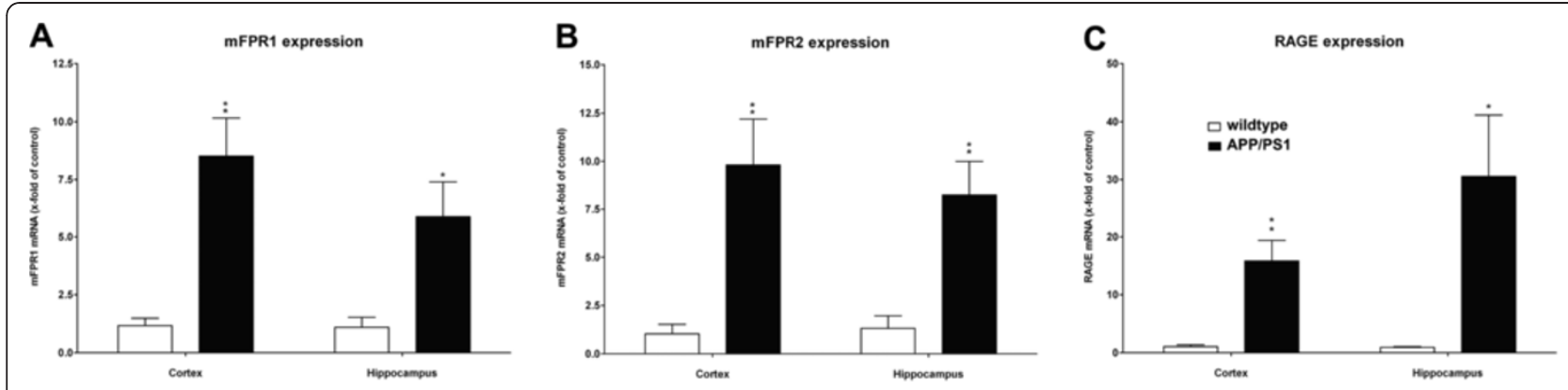

Figure 3 Increased receptor expression in the cortex and hippocampus of twelve month old APP/PS1 transgenic mice. The cortex and hippocampus from twelve month old APP/PS1 or wildtype mice were isolated and mRNA expression of mFPR1 (A), mFPR2 (B) or RAGE (C) were determined using realtime RT-PCR. Data were assessed from six independent experiments in duplicate. An asterisk indicates a significant difference $\left(^{*}=p<0.05 ;{ }^{* *}=p<0.01\right)$ compared to wildtype mice as determined by ANOVA followed by Bonferroni test.

shown in Figure 4E and F, the treatment with forskolin resulted in a strong increase of intracellular cAMP for astrocytes (up to $56 \pm 18 \mathrm{pmol} / \mathrm{ml}$ ) and microglia (up to $38 \pm 15 \mathrm{pmol} / \mathrm{ml}$ ) as compared to untreated cells. The change in the amount of cAMP was calculated as a percentage relative to forskolin. Application of both A $\beta 1-42$ and $\mathrm{AMLF}$ counteracted the forskolin-induced cAMP formation in glial cells and the decrease of cAMP level was strongly inhibited by the formyl peptide receptors antagonist WRW4 [22]. This confirmed our previous results $[11,13]$. In addition, also S100B as well as AGE-BSA reduced forskolin-induced CAMP formation in astrocytes and microglial cells (Figure $4 \mathrm{E}$ and F). Moreover, the S100B- and AGE-BSA-induced decrease of cAMP level was also blocked by the formyl peptide receptors antagonist WRW4. These results suggest that FPR1/FPRL1 is involved in RAGE signalling. WRW4 alone did not alter the forskolin-stimulated adenylate cyclase activity in glial cells.

Detection of the co-localization of RAGE and FPR1 as well as FPRL1 in rat glial and transfected HEK293 cells by immunofluorescence

As described above, S100B- and AGE-BSA-induced ERK1/2 phosphorylation and the reduction of cAMP levels were inhibited by the formyl peptide receptors antagonist WRW4. One can assume that the effects of RAGE are partly mediated by FPR1/FPRL1. To further substantiate our findings, we examined the distribution of FPR1, FPRL1 and RAGE in rat glial cells using double fluorescence microscopy with receptor-specific antibodies. For FPR1 and RAGE, both receptors are co-localised mainly in the plasma membrane in astrocytes as well as microglial cells (Figure 5A). Also FPRL1 showed overlapping staining with RAGE in the plasma membrane of glial cells (Figure 5B). Next, we quantified the colocalisation of fluorescent markers (see methods). The right columns showed the results of a scatter plot of intensities across the two channels (FPR1/FPRL1, green and
RAGE, red). Coefficients of correlations are presented over the scatter plots. The range is from -1 , a strong negative correlation, to +1 , a strong positive correlation. The closer to zero a coefficient is, the weaker the correlation and hence the less evidence there is for colocalisation. The Pearson correlation coefficient $r_{p}$ and Spearman correlation coefficient $r_{s}$ are indicated on the scatter plots. Between FPR1 and RAGE in astrocytes as well as microglial cells, the coefficients illustrate a low co-localisation. For FPRL1 and RAGE, the coefficients confirm a good co-localization.

Furthermore, we analysed the FPR1/FPRL1 and RAGE interaction in transfected HEK293 cells by fluorescence microscopy. Therefore, we stably expressed human FPR1 or FPRL1 and RAGE or a RAGE mutant lacking the cytoplasmic and transducing domain ( $\triangle$ RAGE) in HEK293 cells. As shown in Figure 6A and B, the FPR1 as well as FPRL1 and RAGE are strongly co-localised in plasma membrane. The co-localisation was also quantified and the resulting scatter plot is showed in the right column. The coefficients illustrate a good co-localisation between FPR1 as well as FPRL1 and RAGE as well as $\triangle$ RAGE. We were not able to detect a difference between RAGE and $\triangle$ RAGE for co-localization.

\section{RAGE interacts with FPR1 and FPRL1 in rat glial and transfected HEK293 cells}

To confirm our immunofluorescence results concerning FPR1/FPRL1 and RAGE interaction, co-immunoprecipitation studies were conducted using formyl peptide receptor FPR1 or FPRL1 and RAGE antibodies. FPR1 or FPRL1 receptors were precipitated from lysates of rat glial cells using anti-FPR1 or FPRL1 antibodies. The precipitates were immunoblotted with antibodies directed against FPR1, FPRL1 or RAGE. As shown in Figure 7A RAGE was detected in immunoprecipitates from astrocytes and microglial cells, suggesting that FPR1 or FPRL1 is physically associated with RAGE in vitro and/or under the experimental conditions described. The band densities 


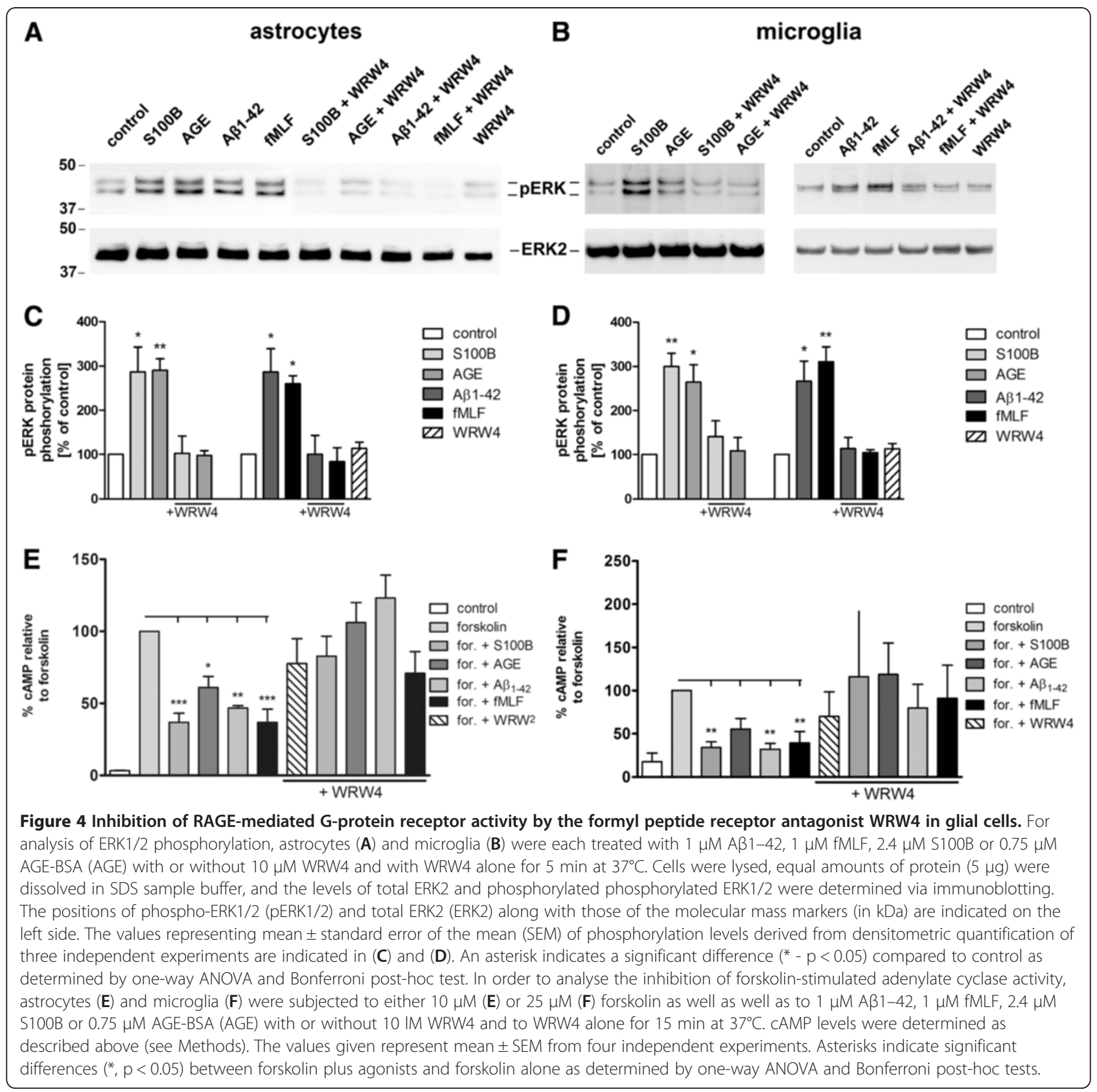

of the western blots were evaluated by densitometric quantification. As shown in Figure 7C, we did not detect a difference between astrocytes and microglial cells for RAGE in FPRL1 as well as FPR1 precipitates, but the amount of co-immunoprecipitated RAGE was higher in FPRL1 precipitates compared to FPR1 precipitates. To confirm the immunoprecipitation, we precipitate RAGE from lysate of astrocytes or microglia. As shown in Figure 7A, FPR1 and FPRL1 were detected in the immunprecipitates.

Furthermore, we analysed the FPR1/FPRL1 and RAGE interaction in transfected HEK293 cells by co-immunoprecipitation. Co-immunoprecipitation studies were conducted with anti-human FPR1 or FPRL1 antibodies using lysates of FPR1/RAGE as well as FPR1/DRAGE or FPRL1-RAGE as well as FPRL1/DRAGE expressing HEK293 cells. The precipitates were immunoblotted with antibodies directed against FPR1, FPRL1 or RAGE. As shown in Figure 7B, RAGE was detected in immunoprecipitates from cotransfected HEK293 cells, which confirms that FPR1 and FPRL1 are physically associated with RAGE in vitro. The mutant receptor $\triangle \mathrm{RAGE}$ was also detected in the FPR1 as well as FPRL1 precipitate. The densitometric quantification of the band densities showed a significant decrease of the amount of co-immunoprecipitated RAGE in the 

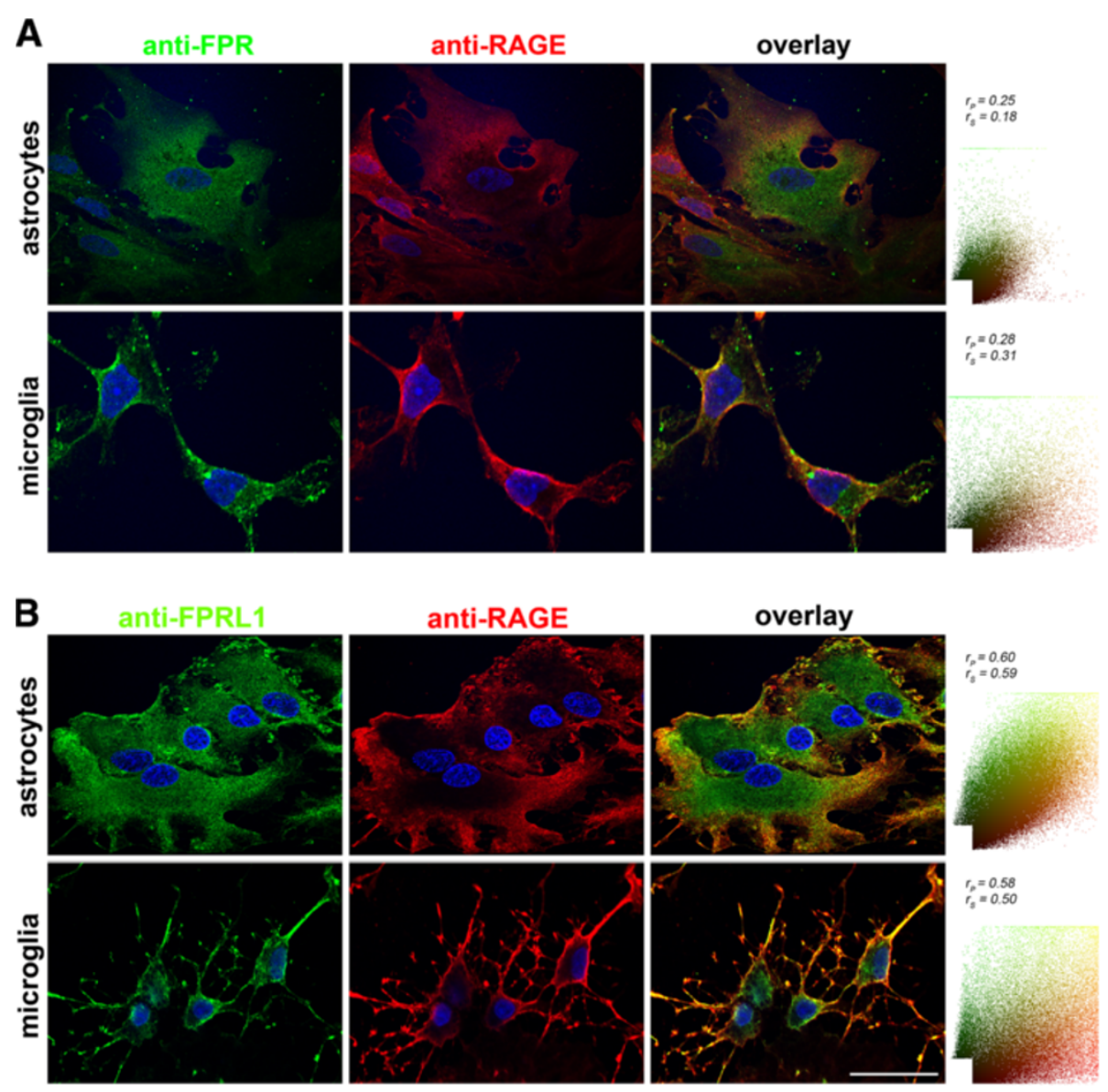

Figure 5 FPR1 and FPRL1 are co-localised with RAGE in primary rat glial cells. Astrocytes and microglial cells were fixed and labelled with anti-FPR1 (A) or anti-FPRL1 (B) and anti-RAGE antibodies. Localisation of FPR1, FPRL1 and RAGE was examined by double fluorescence microscopy. Bisbenzimide was used for nuclear counter-staining (blue). The figures show representative results from one of three independent experiments, each performed in duplicate. Scale bar: $20 \mu \mathrm{m}$. The right columns showed resulting scatter plot of intensities across the two channels. The Pearson correlation coefficient $r_{p}$ and Spearman correlation coefficient $r_{s}$ are indicated on the scatter plots. For FPR1 (green channel) and RAGE (red channel) (A), low co-localisation and for FPRL1 (green channel) and RAGE (red channel) (B) good co-localisation.

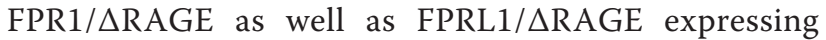
HEK293 cells (Figure 7D).

Next, the protein receptor expression in the cell lysates of glial and transfected HEK293 cells were determined. As shown in Figure 7E, FPR1, FPRL1 and RAGE protein expression were detected in astrocytes, microglia and the corresponding transfected HEK293 cells.

FPR1-, FPRL1- and RAGE-mediated ERK1/2 phosphorylation and change of cAMP levels in transfected HEK293 cells

In an additional set of experiments, we investigated the effect of FPR1, FPRL1 and RAGE on A $31-42-$, fMLF-, $\mathrm{S} 100 \mathrm{~B}$ and AGE-BSA-induced signal transduction in transfected HEK293 cells. For this purpose, we generated FPR1-, FPRL1-, RAGE or $\triangle$ RAGE-expressing, and FPR1 or FPRL1 and RAGE or $\triangle$ RAGE-co-expressing HEK293 cells and analysed ERK1/2 phosphorylation after A $\beta 1-42-$,
fMLF-, S100B and AGE-BSA-treatment. The results of the Western blots were quantified by densitometric quantification. In un-transfected and $\triangle$ RAGE-expressing HEK293 cells, no stimulant resulted in an increase of the ERK1/2 phosphorylation (Figure 8A(a and b)). For RAGE-expressing HEK293 cells, S100B as well as AGE-BSA induced an increase of ERK1/2 phosphorylation in RAGE-expressing cells, whereas A $\beta 1-42$ and fMLF showed no effect (Figure 8A(c)). In FPRL1-transfected and FPRL1- $\triangle$ RAGE-co-expressing HEK293 cells, only A $\beta 1-42$ and fMLF induced an increase of ERK1/2 phosphorylation (Figure $8 \mathrm{~B}(\mathrm{a}$ and $\mathrm{b})$ ), whereas in FPRL1-RAGE-co-expressing HEK293 cells, A $31-42$, fMLF, S100B and AGE-BSA significantly increased ERK1/2 phosphorylation (Figure $8 \mathrm{~B}(\mathrm{c})$ ). Interestingly, in FPR1-expressing and FPR1- $\triangle$ RAGE-co-expressing HEK293 cells, A $\beta 1-42-$ and AMLF- as well as S100B and AGE-BSA induced an increase of ERK1/2 phosphorylation (Figure $8 \mathrm{C}(\mathrm{a}$ and $\mathrm{b})$ ). Furthermore, also in FPR1-RAGE-co-expressing HEK293 

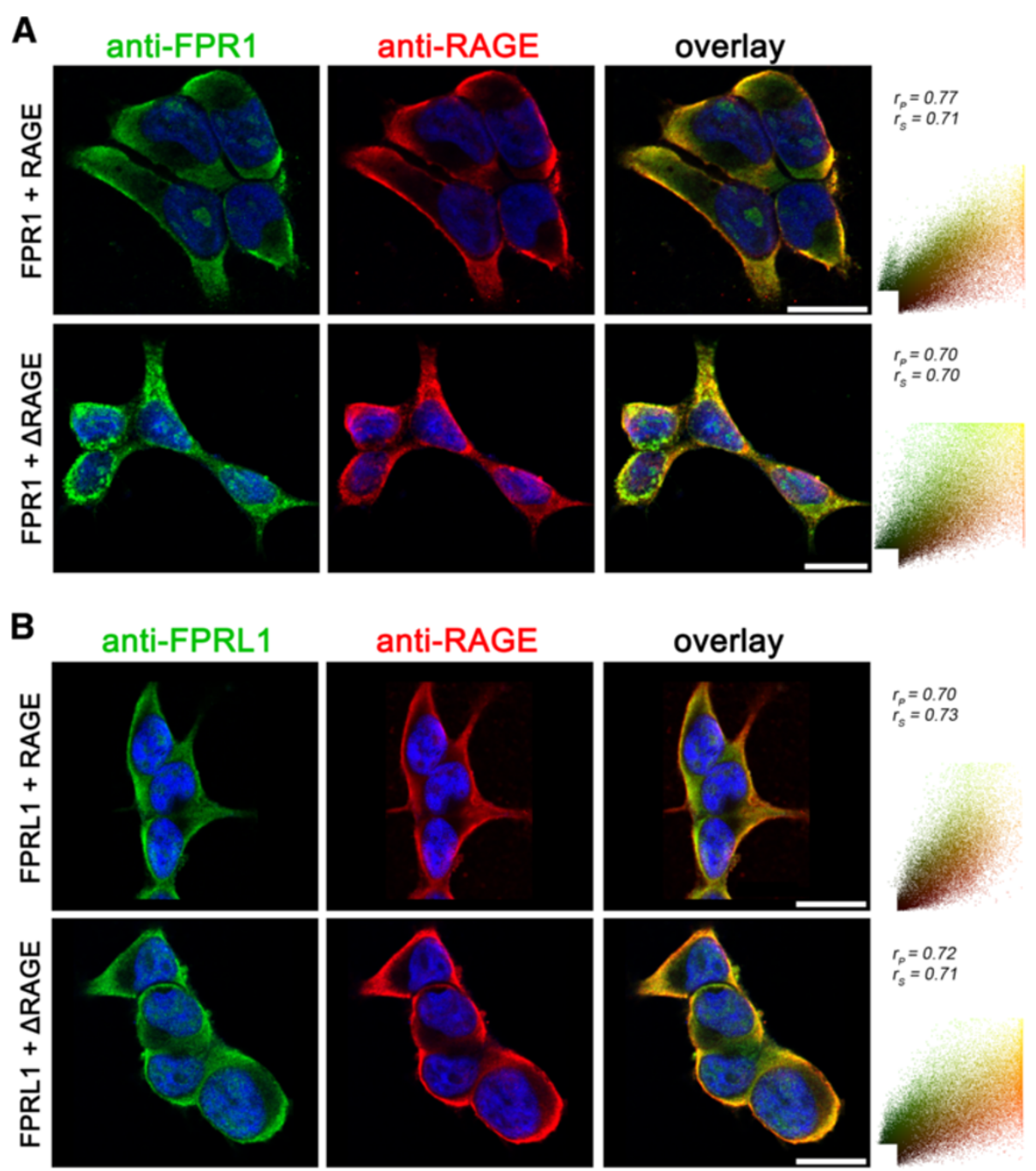

Figure 6 FPR1 and FPRL1 are co-localised with RAGE in transfected HEK293 cells. FPR1 (A) or FPRL1 (B) and RAGE or $\triangle R A G E$ transfected HEK293 cells were fixed and labelled with anti-FPR1 (A) or anti-FPRL1 (B) and anti-RAGE antibodies. Localisation of FPR1, FPRL1 and RAGE/DRAGE was examined by double fluorescence microscopy. Bisbenzimide was used for nuclear counter-staining (blue). The figures show representative results from one of three independent experiments, each performed in duplicate. Scale bar: $20 \mu \mathrm{m}$. The right columns show the resulting scatter plot of intensities across the two channels. The Pearson correlation coefficient $r_{p}$ and Spearman correlation coefficient $r_{s}$ are indicated on the scatter plots. For FPR1/FPRL1 (green channel) and RAGE/DRAGE (red channel), please note a good co-localisation.

cells, A $1-42$, fMLF, S100B and AGE-BSA increased a significantly ERK1/2 phosphorylation (Figure 8C(c)).

The above results are reflected in a change in forskolininduced adenylate cyclase activity. In hFPRL1-expressing and FPRL1- $\triangle$ RAGE-co-expressing cells only the stimulation with $A \beta 1-42$ and fMLF were able to reduce the cAMP level significantly (Figure 9A and C), whereas in FPRL1-RAGE-co-expressing HEK293 cells also S100B and AGE-BSA showed an effect on cAMP level (Figure 9B). Interestingly, in FPR1-expressing HEK293 cells, A $31-42-$ and AMLF- as well as AGE-BSA induced attenuated forskolin-induced cAMP accumulation (Figure 9D). S100B induced a slight but not significant reduction of forskolin-induced adenylate cyclase activation. In FPR1-
RAGE-co-expressing HEK293 cells A $\beta 1-42$, fMLF, S100B and AGE-BSA significantly reduced forskolin-induced cAMP level. In contrast, co-expression with $\triangle$ RAGE cancels the effect of S100B and AGE-BSA compared to $A \beta 1-42$ - as well as fMLF-mediated inhibition of forskolininduced cAMP accumulation (Figure 9E and F). In HEK293 cells, only transfected with RAGE or $\triangle$ RAGE, neither of the agonists induced a change of forskolininduced adenylate cyclase activation (Figure 9G and H).

Different receptors and $S 100 B$ as well as $A \beta 1-42$ co-localization in transfected HEK293 cells

After we were able to demonstrate an involvement of the formyl peptide receptors in S100B- as well as AGE- 


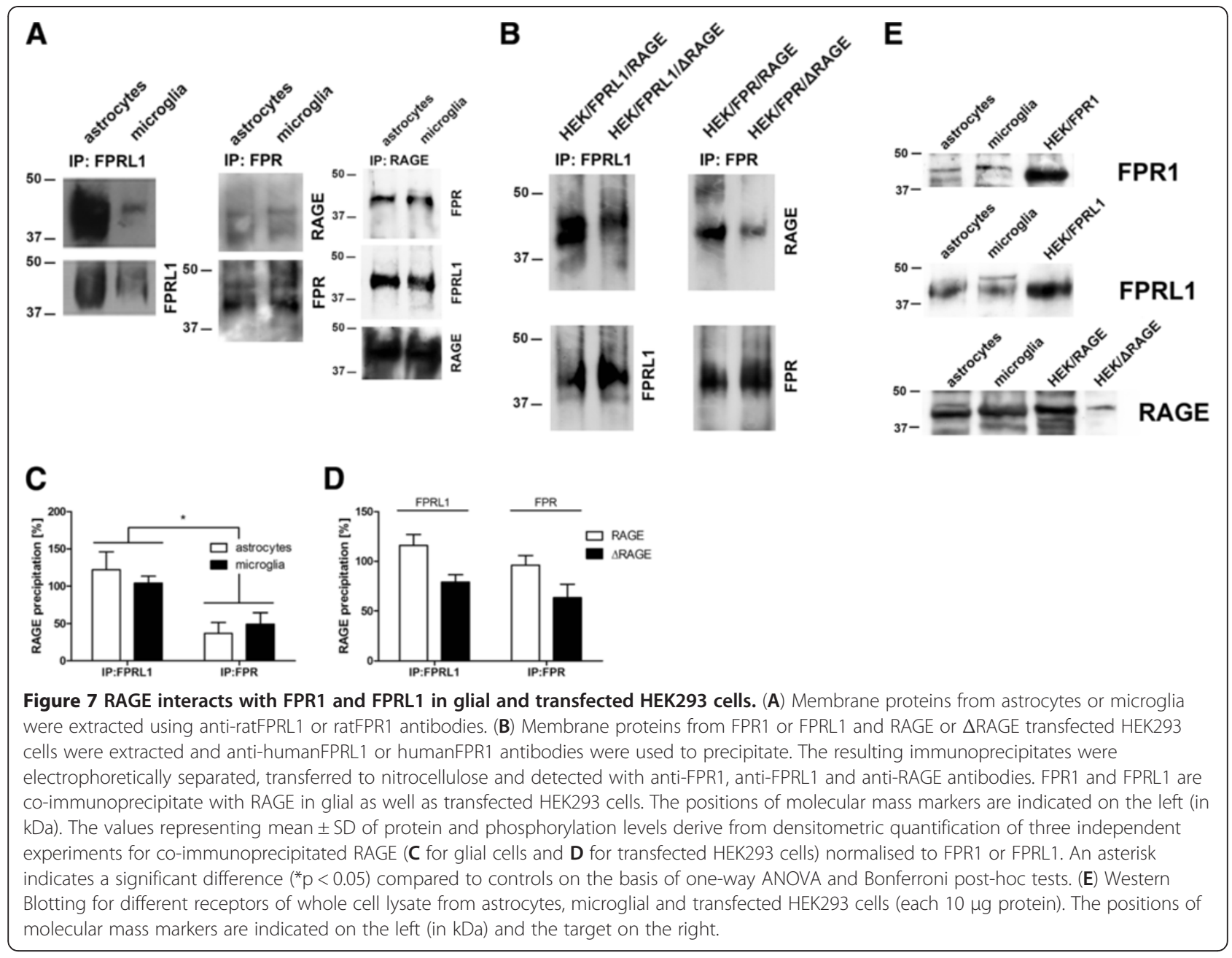

BSA-induced signal transduction, we investigated whether a direct interaction between $\mathrm{S} 100 \mathrm{~B}$ or $\mathrm{A} \beta 1-42$ and the receptors is detectable. Therefore, we analysed and quantified the co-localisation of different receptors with $\mathrm{S} 100 \mathrm{~B}$ as well as A $31-42$ using fluorescence microscopy after treatment of different receptor-expressing HEK293 cells with $\mathrm{S} 100 \mathrm{~B}$ or $\mathrm{A} \beta 1-42$ for $2 \mathrm{~h}$. As shown in Figure 10A, in untranfected HEK293 cells we did not determine a detectable amount of bound S100B. In FPR1 expressing HEK293 cells, a slight increase of S100B in the cells was detectable, whereas in FPRL1 expressing HEK293 some S100B particles were identified. The largest amount of S100B was detected in RAGE expression HEK293 cells. The co-localisation was also quantified and the resulting scatter plot is in the right column. The coefficients illustrate a low but existing co-localisation between FPRL1 as well as RAGE and S100B. Between FPR1 and S100B, the coefficients illustrate a poor colocalisation.

For the A $\beta 1-42$ and the different receptors, the colocalisation was also quantified. The results in Figure 10B show a good co-localisation between A $\beta 1-42$ and FPRL1, whereas the coefficients illustrate a low but existing colocalisation between FPR1 as well as RAGE and A $\beta 1-42$.

\section{Discussion}

Our study shows the involvement of formyl peptide receptors FPR1 and FPRL1 in A $\beta 1$-42-induced signal transduction in glial and transfected HEK293 cells. This confirmed and extended our previous results for the FPRL1 [11,13]. Interestingly, our results also show an involvement of the high affinity receptor FPR1 in A $\beta 1-42-$ induced signal transduction in transfected HEK293 cells. A previous result from Le et al. [29] reported that A $\beta 1-$ 42 is able to activate FPR1 in transfected HEK293 and a rat basophilic leukemia cell line, but that the receptor's efficacy in mediating cell migration and activation is much lower than that of FPRL1. In our transfected HEK293 cells, we did not observe a clear difference between FPR1 and FPRL1 expressing cells in A $\beta 1$-42-induced ERK1/2 phosphorylation or a change of cAMP accumulation (Figures 8 and 9). Our previous results with small 


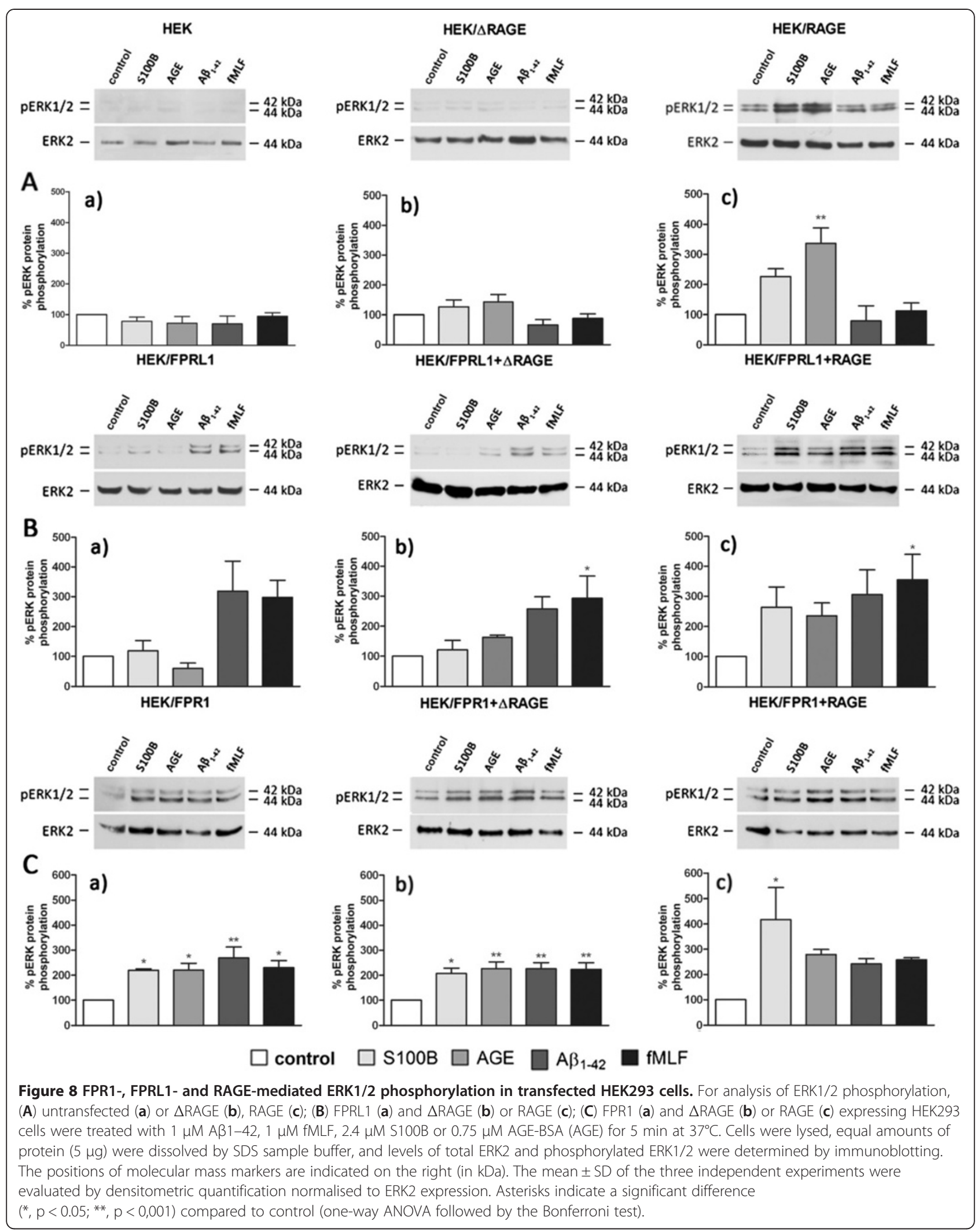




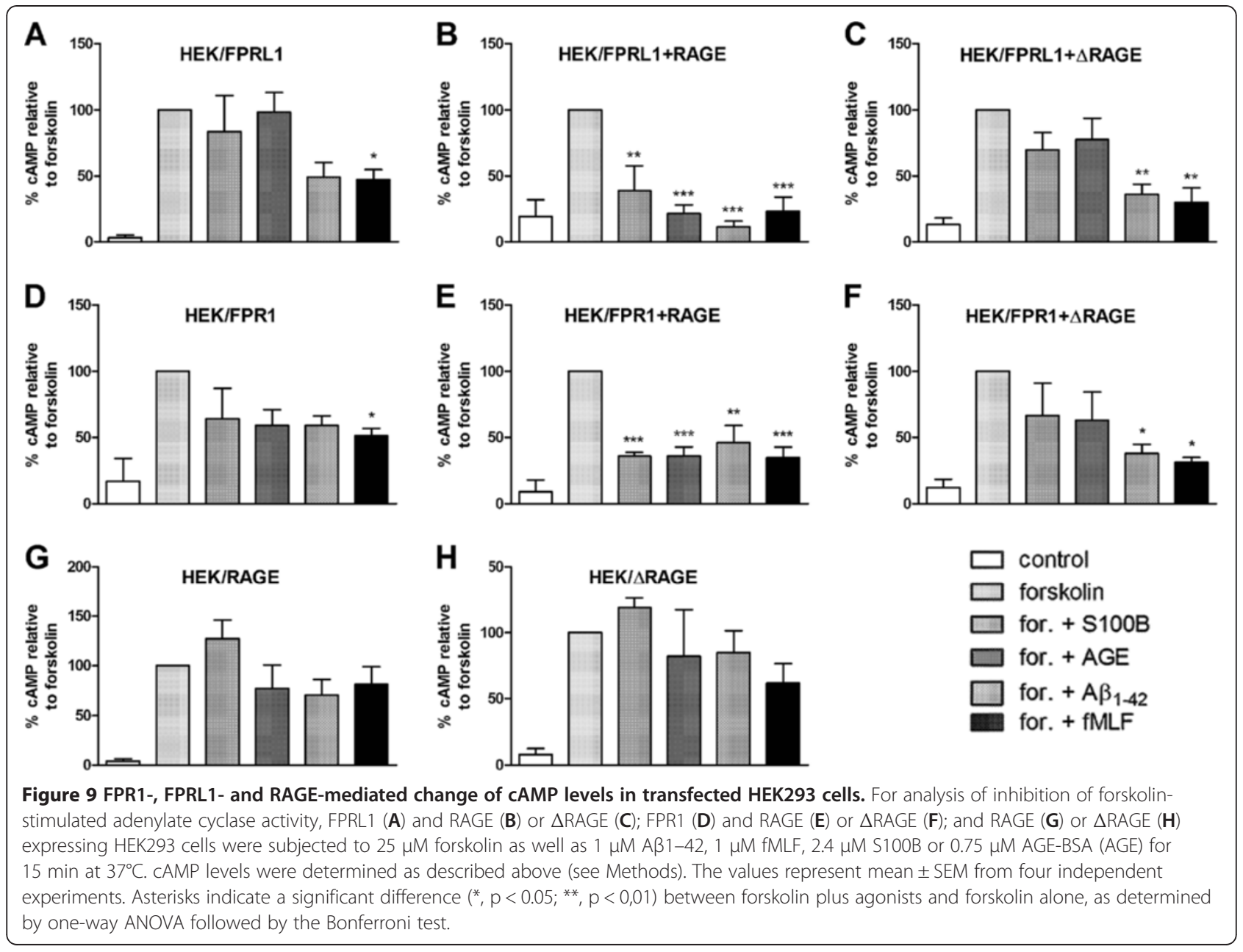

inferring RNA against FPR1 in primary astrocytes did not result in an inhibition of $\mathrm{A} \beta 1$-42-induced ERK1/2 phosphorylation. However, the results could be explained by the low FPR1 expression in the astrocytes as our previous results had shown [11]. It should be noted that microglial cells show a higher endogen FPR1 expression. In addition, other receptors are discussed for A $\beta 1-42-$ induced glial cell activation. Other groups have reported that the scavenger receptor MARCO (macrophage receptor with collagenous structure), a cell surface glycoprotein, plays a role in the internalisation and $A \beta 1-42$ mediated microglia activation [16]. Our previous results in astrocytes and transfected HEK293 cells did not show an involvement of MARCO in A $\beta 1$-42-induced ERK1/2 phosphorylation and change of cAMP accumulation [11]. Recent works suggested that scavenger receptors mediate $A \beta$ internalisation in microglial cells or activation of perivascular macrophages [30,31]. A further receptor, which is discussed in the context of the A $\beta 1$-42-induced glial cell activation, is RAGE. Previous studies had shown that RAGE binds $A \beta 1-42$ with high affinity in microglial cells and neurons [17]. It was suggested that
RAGE-dependent signaling in microglial cells contributes to neuroinflammation and $\mathrm{A} \beta$ accumulation as well as impaired learning/memory in an APP/PS1 transgenic mouse model [32]. The crossing of these mice with an inactive RAGE mutant resulted in a decrease of $A \beta$ levels and amyloid plaque load. It should be noted that other working groups were not able to determine an effect of RAGE in an APP/PS1 transgenic mouse model [33]. However, our present results show a strong increase of mice formyl peptide receptors $\mathrm{mFPR} 1$ and 2 , the mice homologon to human FPR1 and FPRL1, as well as RAGE expression in the hippocampus and for mFPR2 also in the cortex of the used APP/PS1 transgenic mice (Figure 3). Nevertheless, it must be noted that nothing is known about the increase of receptor expression in the human AD brain. The increase was co-localised to astrocytes and microglia cells (Figures 1 and 2). Also for MARCO, we were able to detect a strong increase of expression co-localised to glial cells (data not shown). This extended previous results for RAGE and MARCO [34,35]. Altogether, the increasing receptor expression during the course of $A \beta 1-42$ deposition in APP/PS1 

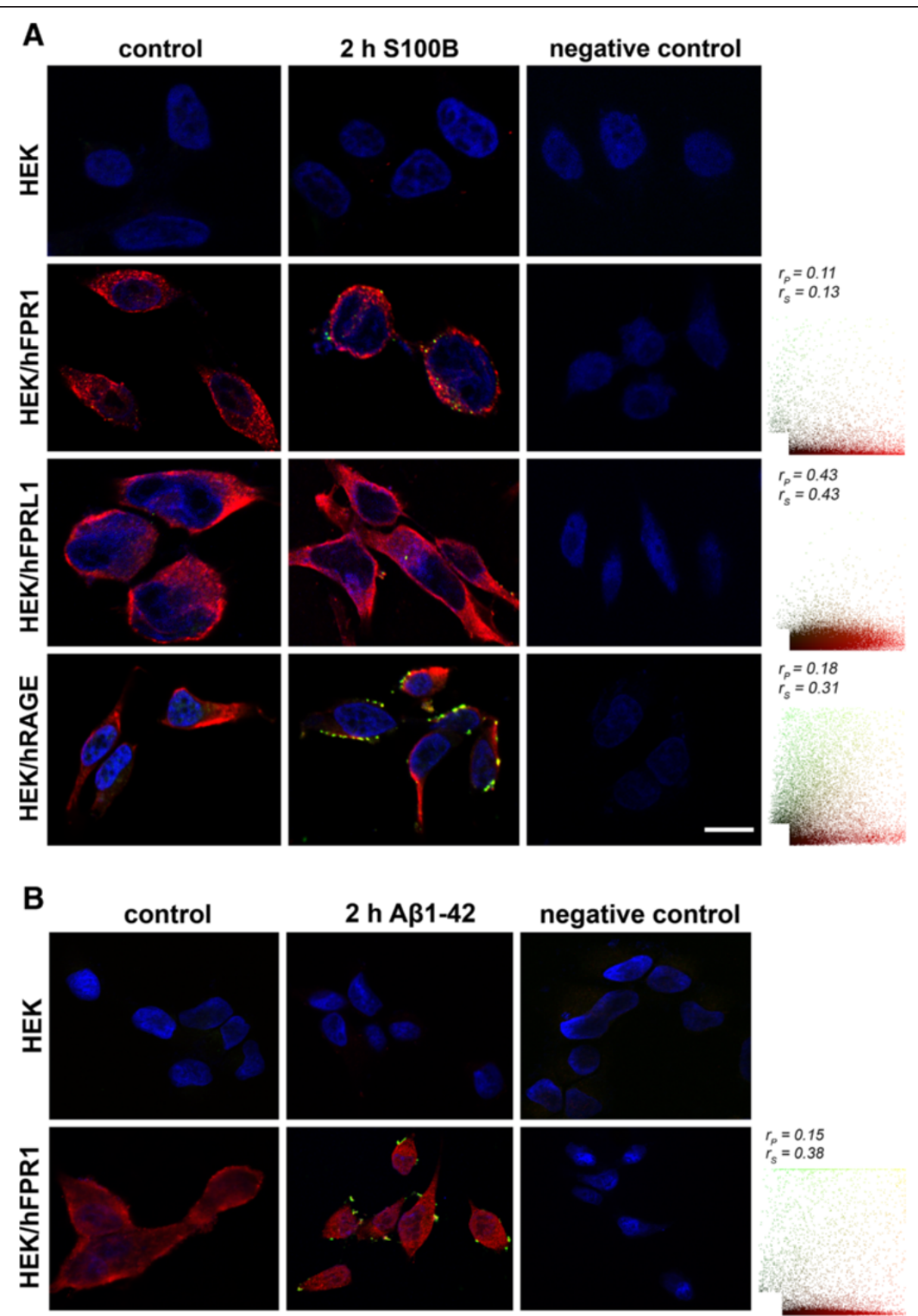

negative control
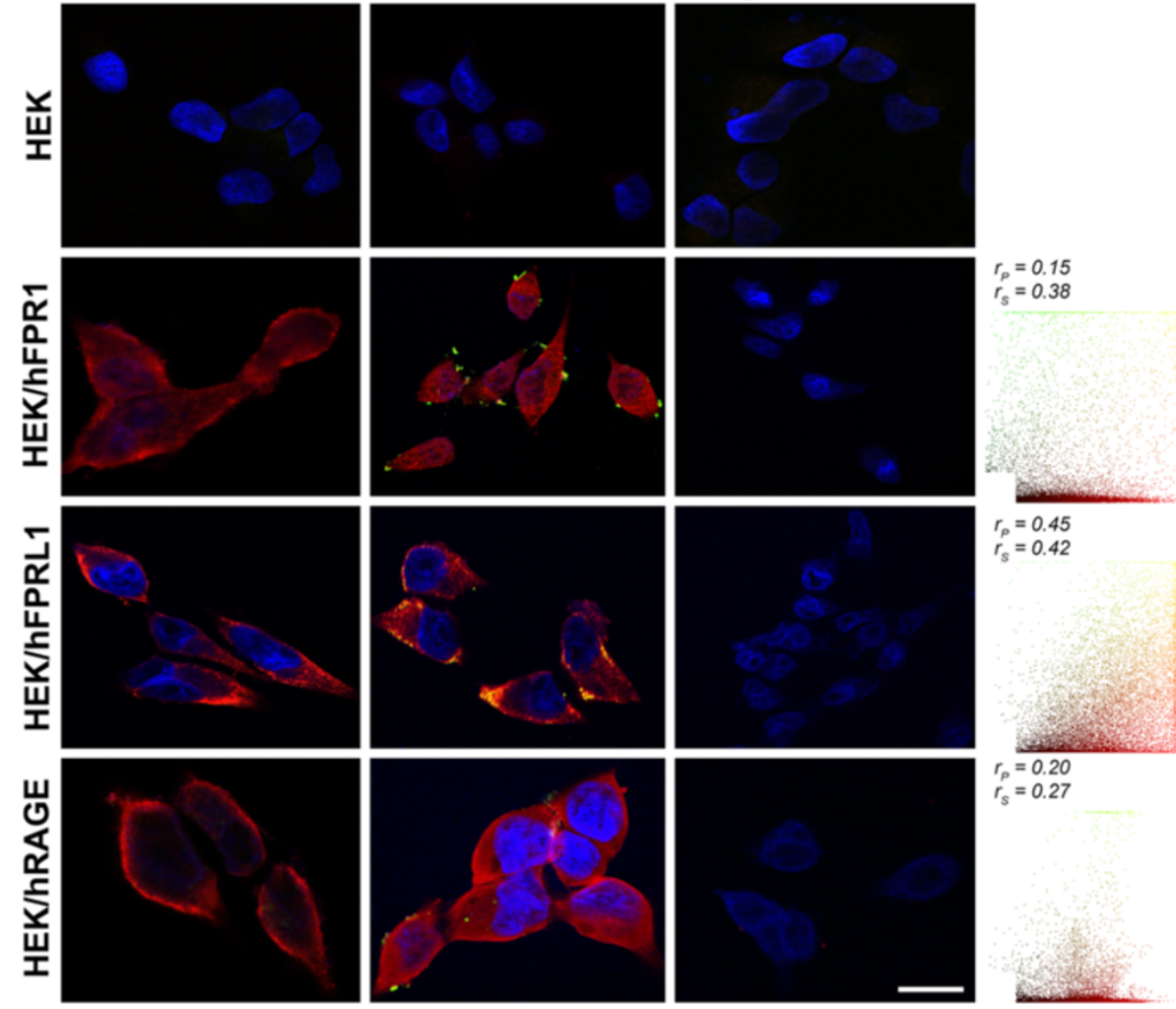

$r_{p}=0.45$

$r_{s}=0.42$

Figure 10 (See legend on next page.) 
(See figure on previous page.)

Figure 10 Different receptors and S100B or A $\beta 1-42$ co-localisation in transfected HEK293 cells. Untransfected or FPR1-, FPRL1- or RAGE expressing HEK293 cells were incubated with $2.4 \mu \mathrm{M}$ S100B or $1 \mu \mathrm{M} \mathrm{AB1-42}$ for $2 \mathrm{~h}$. Cells were fixed and labelled with anti-FPR1, -FPRL1, -RAGE and anti-S100B or anti- AB1-42 antibodies. Localisation of FPR1, FPRL1 or RAGE and S100B (A) or AB1-42 (B) was examined by double

fluorescence microscopy. Bisbenzimide was used for nuclear counter-staining (blue). The figures show representative results from one of three

independent experiments, each performed in duplicate. Scale bar: $20 \mu \mathrm{m}$. The right columns show the resulting scatter plot of intensities across the two channels. The Pearson correlation coefficient $r_{p}$ and Spearman correlation coefficient $r_{s}$ are indicated on the scatter plots. For FPR1 (red channel) and S100B or A 1 1-42 (green channel), poor or low co-localisation; for FPRL1 (red channel) and S100B or A 1 1-42 (green channel), low or good co-localisation and for RAGE (red channel) and S100B or Aß1-42 (green channel), both low co-localisation. transgenic mice could be a sign of enhanced inflammation including glial cell activation. The receptor activation of different signal transduction pathways including NADPH oxidase or NFKB is increased. This may be associated with an increased production of proinflammatory cytokines and reactive oxygen species [36-38]. However, a recent study showed that the mFPR2 acted as an antiinflammatory receptor [39]. It could also be a sign of the increased uptake and clearance of $A \beta$. Our previous work showed the involvement of FPRL1 in glial cells mediated A 1 1-42 internalisation [13]. Possible, the increase of receptor expression represents a protective function against increased $A \beta$ concentration in the brain. The receptor-mediated internalisation could be an interesting point to influence the plaque as well as $\mathrm{AD}$ development. In this context, previous results showed that the glial cells are able to internalise $A \beta$, although the uptake is dependant on $A \beta$ forms and size [13,40-42]. Further studies must explore this topic.

Interestingly, in this study, we have demonstrated a physical interaction between FPR1 or FPRL1 and RAGE in glial and transfected HEK293 cells by co-immunoprecipitation and fluorescence microscopy for the first time (Figures 5 6 7). The densitometric quantification and quantitative statistical co-localisation show that the interaction was stronger between FPRL1 and RAGE compared to FPR1 and RAGE in glial cells. Differences between astrocytes, microglial cells and in transfected HEK293 cells were detectable. In FPR1 as well as FPRL1 and $\triangle$ RAGE, a RAGE mutant lacking the cytoplasmic and transducing domain, co-expressing HEK293 cells, showed that the interaction was significantly but not completely reduced (Figure 7 ). The intracellular domain is possibly involved in the binding between FPR1/FPRL1 and RAGE. The function of this interaction remains unclear. However, our previous results showed a physical and functional interaction between FPR1/FPRL1 and MARCO [11]. The findings suggest that the receptors interaction influences the receptor activity by cross-phosphorylation and desensitisation of downstream signalling pathways. Such influence was also detected for other receptor classes. For example, studies have shown an extensive cross-talk between opioid- and somatostatin-receptors mediated analgesic responses and pain-processing pathways $[43,44]$. For the interaction between FPR1/FPRL1 and MARCO as well as RAGE, it is possible that the pattern recognition receptors complement, modulate and enhance each other of their effects. By this, they could enhance the response of the innate immune system or even the inflammatory response in Alzheimer's disease.

For the signal transduction pathways, our results for ERK1/2 phosphorylation and the change of cAMP accumulation show that the specific formyl peptide receptors antagonist WRW4 inhibited RAGE ligands S100B- as well as AGE-BSA-induced glial cell activation (Figure 4). Furthermore, the findings confirmed the importance of the FPRL1 in Aß1-42-induced signal transduction. However, the results with transfected HEK293 cells showed that S100B- or AGE-BSA-induced ERK1/2 phosphorylation and inhibition of cAMP level is not mediated by FPRL1, whereas FPR1 is involved (Figures 8 and 9). Interestingly, FPR1 expressing HEK293 cells also mediate an A $31-42$-induced ERK1/2 phosphorylation and a change of cAMP accumulation, whereas our results did not confirm an involvement of RAGE. In addition, a cotransfection of RAGE in FPR1 or FPRL1 expressing cells resulted in an amplification of the S100B- as well as AGE-BSA-induced signal transduction. For the involvement of the receptors in S100B or A $\beta 1-42$-induced signalling, the immunofluorescence and quantitative statistical co-localisation confirmed that RAGE but also FPR1 binding S100B, whereas the co-localisation of $A \beta 1-42$ and FPRL1 is strongest (Figure 10). Altogether, the findings suggest complementary and synergic action between the receptors. The elucidation of consequences for receptor activities and inflammation as well as the progression of the AD need further investigations. Nevertheless, previous kinetics studies showed a binding of $A \beta$ and RAGE in endothelial cells and cortical neurons [45]. I can be assumed that the binding depends on the $A \beta$ forms (monomeric, oligomeric or fibrillary). For the present study, we used non-fibrillary A $\beta 1-42$. In addition, it must be noted that in the primary cells, the mediation of the effect by other receptors cannot be excluded. Furthermore, it was shown that microglial cells behave differently depending upon age in interaction with fibrillary 
A $\beta$ [46]. Further studies with receptor-deficient cells should bring more clarity here.

In conclusion, there is a substantial interest to identify the cell surface receptors that bind and mediate the intracellular effects of A $\beta 1-42$ in glial cells. Consequently, FPR1/ FPRL1 and RAGE or MARCO interactions may explain how formyl peptide receptors interact with a menagerie of structurally diverse pro- and anti-inflammatory ligands associated with different diseases including amyloidosis, Alzheimer's disease, prion disease and HIV, or with bacterial components $[14,21]$. Interactions with other receptors may support and modulate the cellular reaction to such structurally diverse ligands by the formyl peptide receptors. Altogether, we hypothesise that formyl peptide receptors play a central role in neurodegenerative mechanisms and physiological regulatory processes.

\section{Abbreviations \\ A $\beta$ : Amyloid- $\beta$-peptide; DMEM: Dulbecco's modified Eagle's medium; ERK: Extracellular signal-regulated kinases; FCS: Fetal calf serum; fMLF: Formyl- methionyl-leucyl-proline; FPRL1: Formyl peptide receptor like-1; GFAP: Glial fibrillary acidic protein; MARCO: Macrophage receptor with collagenous structure; RAGE: Receptor for advanced glycation endproducts.}

\section{Competing interests}

The authors declare that they have no competing interests.

\section{Authors' contributions}

$A S, J M$ and $L O B$ designed as well as performed experiments, and drafted the manuscript. AE and FM performed experiments. SJ helped to accomplish experiments and revised the manuscript. CJW and TP co-conceived of the study, participated in its design and coordination, and helped draft the manuscript. All authors have read and approved the final version of this manuscript.

\section{Acknowledgment}

We thank Susanne Echterhagen, Michaela Nicolau and Lian Shen for excellent technical assistance. This study was supported by the STARTProgram of the RWTH Aachen University (Germany, to L.O.B.).

\section{Author details}

'Department of Anatomy and Cell Biology, RWTH Aachen University, Wendlingweg 2, 52074 Aachen, Germany. ${ }^{2}$ Department of Neuroanatomy, RWTH Aachen University, Aachen, Germany.

Received: 8 June 2012 Accepted: 15 November 2012 Published: 20 November 2012

\section{References}

1. Selkoe DJ: Alzheimer's disease results from the cerebral accumulation and cytotoxicity of amyloid beta-protein. J Alzheimers Dis 2001, 3:75-80.

2. White JA, Manelli AM, Holmberg KH, Van Eldik LJ, Ladu MJ: Differential effects of oligomeric and fibrillar amyloid-beta 1-42 on astrocytemediated inflammation. Neurobiol Dis 2005, 18:459-465.

3. Parvathy S, Rajadas J, Ryan H, Vaziri S, Anderson L, Murphy GM Jr: Abeta peptide conformation determines uptake and interleukin-1alpha expression by primary microglial cells. Neurobiol Aging 2009, 30:1792-1804

4. Murgas P, Godoy B, von Bernhardi R: Abeta potentiates inflammatory activation of glial cells induced by scavenger receptor ligands and inflammatory mediators in culture. Neurotox Res 2012, 22:69-78.

5. Sondag CM, Dhawan G, Combs CK: Beta amyloid oligomers and fibrils stimulate differential activation of primary microglia. I Neuroinflammation 2009, 6:1.
6. Eikelenboom P, van Exel E, Hoozemans JJ, Veerhuis R, Rozemuller AJ, van Gool WA: Neuroinflammation - an early event in both the history and pathogenesis of Alzheimer's disease. Neurodegener Dis 2010, 7:38-41.

7. Eikelenboom P, Veerhuis R, Scheper W, Rozemuller AJ, van Gool WA, Hoozemans JJ: The significance of neuroinflammation in understanding Alzheimer's disease. J Neural Transm 2006, 113:1685-1695.

8. Eikelenboom P, Bate C, Van Gool WA, Hoozemans JJ, Rozemuller JM, Veerhuis R, Williams A: Neuroinflammation in Alzheimer's disease and prion disease. Glia 2002, 40:232-239.

9. Nagele RG, D'Andrea MR, Anderson WJ, Wang HY: Intracellular accumulation of beta-amyloid(1-42) in neurons is facilitated by the alpha 7 nicotinic acetylcholine receptor in Alzheimer's disease. Neuroscience 2002, 110:199-211.

10. Nagele RG, Wegiel J, Venkataraman V, Imaki H, Wang KC, Wegiel J: Contribution of glial cells to the development of amyloid plaques in Alzheimer's disease. Neurobiol Aging 2004, 25:663-674.

11. Brandenburg LO, Konrad M, Wruck CJ, Koch T, Lucius R, Pufe T: Functional and physical interactions between formyl-peptide-receptors and scavenger receptor MARCO and their involvement in amyloid beta 1-42induced signal transduction in glial cells. J Neurochem 2010, 113:749-760.

12. Brandenburg LO, Koch T, Sievers J, Lucius R: Internalization of PrP106-126 by the formyl-peptide-receptor-like-1 in glial cells. J Neurochem 2007, 101:718-728.

13. Brandenburg LO, Konrad M, Wruck C, Koch T, Pufe T, Lucius R: Involvement of formyl-peptide-receptor-like-1 and phospholipase $D$ in the internalization and signal transduction of amyloid beta 1-42 in glial cells. Neuroscience 2008, 156:266-276.

14. Braun BJ, Slowik A, Leib SL, Lucius R, Varoga D, Wruck CJ, Jansen $S$, Podschun R, Pufe T, Brandenburg LO: The formyl peptide receptor like-1 and scavenger receptor MARCO are involved in glial cell activation in bacterial meningitis. J Neuroinflammation 2011, 8:11.

15. Alarcon R, Fuenzalida C, Santibanez M, von Bernhardi R: Expression of scavenger receptors in glial cells. Comparing the adhesion of astrocytes and microglia from neonatal rats to surface-bound beta-amyloid. J Biol Chem 2005, 280:30406-30415.

16. Paresce DM, Ghosh RN, Maxfield FR: Microglial cells internalize aggregates of the Alzheimer's disease amyloid beta-protein via a scavenger receptor. Neuron 1996, 17:553-565.

17. Yan SD, Chen X, Fu J, Chen M, Zhu H, Roher A, Slattery T, Zhao L, Nagashima M, Morser J, et al: RAGE and amyloid-beta peptide neurotoxicity in Alzheimer's disease. Nature 1996, 382:685-691.

18. Kraal G, van der Laan L, Elomaa O, Tryggvason K: The macrophage receptor MARCO. Microbes Infect 2000, 2:313-316.

19. Mukhopadhyay S, Gordon S: The role of scavenger receptors in pathogen recognition and innate immunity. Immunobiology 2004, 209:39-49.

20. Bierhaus A, Humpert PM, Morcos M, Wendt T, Chavakis T, Arnold B, Stern DM, Nawroth PP: Understanding RAGE, the receptor for advanced glycation end products. J Mol Med 2005, 83:876-886.

21. Le Y, Murphy PM, Wang JM: Formyl-peptide receptors revisited. Trends Immunol 2002, 23:541-548.

22. Bae YS, Lee HY, Jo EJ, Kim JI, Kang HK, Ye RD, Kwak JY, Ryu SH: Identification of peptides that antagonize formyl peptide receptor-like 1-mediated signaling. J Immunol 2004, 173:607-614.

23. Jankowsky JL, Younkin LH, Gonzales V, Fadale DJ, Slunt HH, Lester HA, Younkin SG, Borchelt DR: Rodent A beta modulates the solubility and distribution of amyloid deposits in transgenic mice. J Biol Chem 2007, 282:22707-22720.

24. Bianchi R, Giambanco I, Donato R: S100B/RAGE-dependent activation of microglia via NF-kappaB and AP-1 Co-regulation of COX-2 expression by S100B, IL-1 beta and TNF-alpha. Neurobiol Aging 2008, 31:665-677.

25. McCarthy KD, de Vellis J: Preparation of separate astroglial and oligodendroglial cell cultures from rat cerebral tissue. J Cell Biol 1980, 85:890-902.

26. Brandenburg LO, Seyferth $S$, Wruck CJ, Koch T, Rosenstiel P, Lucius R, Pufe T: Involvement of Phospholipase D 1 and 2 in the subcellular localization and activity of formyl-peptide-receptors in the human colonic cell line HT29. Mol Membr Biol 2009, 26:371-383.

27. French AP, Mills S, Swarup R, Bennett MJ, Pridmore TP: Colocalization of fluorescent markers in confocal microscope images of plant cells. Nat Protoc 2008, 3:619-628. 
28. Abramoff MDM, Paulo J, Ram, Sunanda J: Image processing with ImageJ. Biophotonics international 2004, 11:36-42.

29. Le Y, Gong W, Tiffany HL, Tumanov A, Nedospasov S, Shen W, Dunlop NM, Gao JL, Murphy PM, Oppenheim JJ, Wang JM: Amyloid (beta)42 activates a G-protein-coupled chemoattractant receptor, FPR-like-1. J Neurosci 2001, 21:RC123.

30. Yang CN, Shiao YJ, Shie FS, Guo BS, Chen PH, Cho CY, Chen YJ, Huang FL, Tsay HJ: Mechanism mediating oligomeric Abeta clearance by naive primary microglia. Neurobiol Dis 2011, 42:221-230.

31. Thanopoulou K, Fragkouli A, Stylianopoulou F, Georgopoulos S: Scavenger receptor class B type I (SR-BI) regulates perivascular macrophages and modifies amyloid pathology in an Alzheimer mouse model. Proc Natl Acad Sci U S A 2010, 107:20816-20821.

32. Fang F, Lue LF, Yan S, Xu H, Luddy JS, Chen D, Walker DG, Stern DM, Yan S, Schmidt AM, et al: RAGE-dependent signaling in microglia contributes to neuroinflammation, Abeta accumulation, and impaired learning/memory in a mouse model of Alzheimer's disease. FASEB J 2010, 24:1043-1055.

33. Vodopivec I, Galichet A, Knobloch M, Bierhaus A, Heizmann CW, Nitsch RM: RAGE does not affect amyloid pathology in transgenic ArcAbeta mice. Neurodegener Dis 2009, 6:270-280.

34. Mulder SD, Veerhuis R, Blankenstein MA, Nielsen HM: The effect of amyloid associated proteins on the expression of genes involved in amyloid-beta clearance by adult human astrocytes. Exp Neurol 2012, 233:373-379.

35. Valente T, Gella A, Fernandez-Busquets X, Unzeta M, Durany N: Immunohistochemical analysis of human brain suggests pathological synergism of Alzheimer's disease and diabetes mellitus. Neurobiol Dis 2010, 37:67-76.

36. Han SH, Kim YH, Mook-Jung I: RAGE: the beneficial and deleterious effects by diverse mechanisms of actions. Mol Cells 2011, 31:91-97.

37. Tiffany $\mathrm{HL}$, Lavigne MC, Cui YH, Wang JM, Leto TL, Gao JL, Murphy PM: Amyloid-beta induces chemotaxis and oxidant stress by acting at formylpeptide receptor 2, a G protein-coupled receptor expressed in phagocytes and brain. J Biol Chem 2001, 276:23645-23652.

38. Rabiet MJ, Huet E, Boulay F: The N-formyl peptide receptors and the anaphylatoxin C5a receptors: an overview. Biochimie 2007, 89:1089-1106.

39. Dufton N, Hannon R, Brancaleone V, Dalli J, Patel HB, Gray M, D'Acquisto F, Buckingham JC, Perretti M, Flower RJ: Anti-inflammatory role of the murine formyl-peptide receptor 2: ligand-specific effects on leukocyte responses and experimental inflammation. J Immunol 2010, 184:2611-2619.

40. Nielsen HM, Mulder SD, Belien JA, Musters RJ, Eikelenboom P, Veerhuis R: Astrocytic $A$ beta 1-42 uptake is determined by $A$ beta-aggregation state and the presence of amyloid-associated proteins. Glia 2010, 58:1235-1246.

41. Nielsen HM, Veerhuis R, Holmqvist B, Janciauskiene S: Binding and uptake of A beta1-42 by primary human astrocytes in vitro. Glia 2009, 57:978-988

42. Pan XD, Zhu YG, Lin N, Zhang J, Ye QY, Huang HP, Chen XC: Microglial phagocytosis induced by fibrillar beta-amyloid is attenuated by oligomeric beta-amyloid: implications for Alzheimer's disease. Mol Neurodegener 2011, 6:45.

43. Betoin F, Ardid D, Herbet A, Aumaitre O, Kemeny JL, Duchene-Marullaz P, Lavarenne J, Eschalier A: Evidence for a central long-lasting antinociceptive effect of vapreotide, an analog of somatostatin, involving an opioidergic mechanism. J Pharmacol Exp Ther 1994, 269:7-14.

44. Pfeiffer M, Koch T, Schroder H, Laugsch M, Hollt V, Schulz S: Heterodimerization of somatostatin and opioid receptors crossmodulates phosphorylation, internalization, and desensitization. J Biol Chem 2002, 277:19762-19772.

45. Yan SD, Stern D, Kane MD, Kuo YM, Lampert HC, Roher AE: RAGE-Abeta interactions in the pathophysiology of Alzheimer's disease. Restor Neurol Neurosci 1998, 12:167-173.

46. Floden AM, Combs CK: Microglia demonstrate age-dependent interaction with amyloid-beta fibrils. J Alzheimers Dis 2011, 25:279-293.

doi:10.1186/1750-1326-7-55

Cite this article as: Slowik et al:: Involvement of formyl peptide receptors in receptor for advanced glycation end products (RAGE) - and amyloid beta 1-42-induced signal transduction in glial cells. Molecular Neurodegeneration 2012 7:55.

\section{Submit your next manuscript to BioMed Central and take full advantage of:}

- Convenient online submission

- Thorough peer review

- No space constraints or color figure charges

- Immediate publication on acceptance

- Inclusion in PubMed, CAS, Scopus and Google Scholar

- Research which is freely available for redistribution 